\title{
Photochemistry and Spectral Characterization of Temperate and Gas-rich Exoplanets
}

\author{
Renyu $\mathrm{Hu}^{1,2,3,4}$ (i) \\ ${ }^{1}$ Jet Propulsion Laboratory, California Institute of Technology, Pasadena, CA 91109, USA; renyu.hu@jpl.nasa.gov \\ ${ }^{2}$ Division of Geological and Planetary Sciences, California Institute of Technology, Pasadena, CA 91125, USA \\ Received 2021 February 17; revised 2021 July 16; accepted 2021 July 22; published 2021 October 28
}

\begin{abstract}
Exoplanets that receive stellar irradiance approximately equal to Earth's or less have been discovered and many are suitable for spectral characterization. Here, we focus on the temperate planets that have massive $\mathrm{H}_{2}$-dominated atmospheres, and trace the chemical reactions and transport following the photodissociation of $\mathrm{H}_{2} \mathrm{O}, \mathrm{CH}_{4}, \mathrm{NH}_{3}$, and $\mathrm{H}_{2} \mathrm{~S}$, with $\mathrm{K} 2-18 \mathrm{~b}, \mathrm{PH} 2 \mathrm{~b}$, and Kepler-167 e representing temperate/cold planets around $\mathrm{M}$ and $\mathrm{G} / \mathrm{K}$ stars. We find that $\mathrm{NH}_{3}$ is likely depleted by photodissociation to the cloud deck on planets around $\mathrm{G} / \mathrm{K}$ stars but remains intact in the middle atmosphere of planets around $\mathrm{M}$ stars. A common phenomenon on temperate planets is that the photodissociation of $\mathrm{NH}_{3}$ in the presence of $\mathrm{CH}_{4}$ results in $\mathrm{HCN}$ as the main photochemical product. The photodissociation of $\mathrm{CH}_{4}$ together with $\mathrm{H}_{2} \mathrm{O}$ leads to $\mathrm{CO}$ and $\mathrm{CO}_{2}$, and the synthesis of hydrocarbon is suppressed. Temperate planets with a supersolar atmospheric metallicity and appreciable internal heat may have additional $\mathrm{CO}$ and $\mathrm{CO}_{2}$ from the interior and less $\mathrm{NH}_{3}$, and thus less $\mathrm{HCN}$. Our models of $\mathrm{K} 2-18 \mathrm{~b}$ can explain the transmission spectrum measured by the Hubble Space Telescope, and indicate that future observations in $0.5-5.0 \mu \mathrm{m}$ wavelength range would provide the sensitivity to detect the equilibrium gases $\mathrm{CH}_{4}, \mathrm{H}_{2} \mathrm{O}$, and $\mathrm{NH}_{3}$, the photochemical gas $\mathrm{HCN}$, as well as $\mathrm{CO}_{2}$ in some cases. Temperate and $\mathrm{H}_{2}$-rich exoplanets are thus laboratories of atmospheric chemistry that operate in regimes not found in the solar system, and spectral characterization of these planets in transit or reflected starlight promises to greatly expand the types of molecules detected in exoplanet atmospheres.
\end{abstract}

Unified Astronomy Thesaurus concepts: Exoplanet atmospheres (487); Extrasolar gaseous planets (2172); Extrasolar ice giants (2024); Mini Neptunes (1063); Habitable zone (696); Transmission spectroscopy (2133)

\section{Introduction}

The era of characterizing temperate exoplanets has begun. Kepler, K2, and TESS missions have found a few tens of exoplanets cold enough for water to condense in their atmospheres in transiting orbits (from the NASA Exoplanet Archive). Another handful of temperate planets may be confirmed in the next few years with ongoing validation and follow-up of TESS planet candidates (Barclay et al. 2018). A small subset of these planets has been observed by the Hubble Space Telescope (HST) for transmission spectra (De Wit et al. 2018; Zhang et al. 2018; Benneke et al. 2019; Tsiaras et al. 2019). For example, a transmission spectrum obtained by the HST at $1.1-1.7 \mu \mathrm{m}$ of the temperate sub-Neptune $\mathrm{K} 2-18 \mathrm{~b}$ shows spectral features (Benneke et al. 2019; Tsiaras et al. 2019), and the spectrum indicates that the planet hosts an atmosphere dominated by $\mathrm{H}_{2}$, and which includes $\mathrm{H}_{2} \mathrm{O}$ and/or $\mathrm{CH}_{4}$ (Benneke et al. 2019; Madhusudhan et al. 2020; Blain et al. 2021). TOI-1231 b is another temperate planet suitable for atmospheric studies with transits (Burt et al. 2021). With $>7$ times more collecting area and infrared instruments, the James Webb Space Telescope (JWST) will be capable of providing a more detailed look into the atmospheres of these temperate exoplanets (Beichman et al. 2014).

We refer to the exoplanets that receive stellar irradiance approximately equal to Earth's as "temperate exoplanets" and to those that receive less irradiance by approximately an order of magnitude as "cold exoplanets" in this paper. Temperate and cold exoplanets include both giant planets and small planets and potentially have diverse atmospheric compositions. Giant

\footnotetext{
3 @2021 California Institute of Technology.

${ }^{4}$ Government sponsorship acknowledged.
}

planets (Jupiters and Neptunes) have massive $\mathrm{H}_{2} / \mathrm{He}$ envelopes (e.g., Burrows et al. 2001), and small planets (mini-Neptunes, super-Earths, and Earth-sized planets) can have $\mathrm{H}_{2} / \mathrm{He}$ atmospheres with variable abundances of heavy elements, steam atmospheres mostly made of water, or secondary atmospheres from outgassing (e.g., Fortney et al. 2013; Moses et al. 2013; Hu \& Seager 2014).

In this paper, we focus on temperate/cold and gas-rich exoplanets, which include temperate/cold giant planets and mini-Neptunes. We assume that the atmospheres are $\mathrm{H}_{2} /$ He-dominated and massive enough for thermochemical equilibrium to prevail at at the bottom. This condition determines that the dominant $\mathrm{O}, \mathrm{C}, \mathrm{N}$, and $\mathrm{S}$ species should be $\mathrm{H}_{2} \mathrm{O}, \mathrm{CH}_{4}, \mathrm{NH}_{3}$, and $\mathrm{H}_{2} \mathrm{~S}$ on temperate and cold planets in most cases (e.g., Fegley \& Lodders 1996; Burrows \& Sharp 1999; Heng \& Tsai 2016; Woitke et al. 2021). Thermochemical equilibrium may also produce $\mathrm{N}_{2}$ as the dominant $\mathrm{N}$ species and a substantial abundance of $\mathrm{CO}$ and $\mathrm{CO}_{2}$ if the planet has a hot interior (e.g., Fortney et al. 2020). On temperate and cold planets, $\mathrm{H}_{2} \mathrm{O}$ can condense to form a cloud, and the abovecloud $\mathrm{H}_{2} \mathrm{O}$ is partially depleted as a result (e.g., Morley et al. 2014; Hu 2019; Charnay et al. 2021). Cold planets may additionally have $\mathrm{NH}_{4} \mathrm{SH}$ (from the combination reaction between $\mathrm{NH}_{3}$ and $\mathrm{H}_{2} \mathrm{~S}$ ) and $\mathrm{NH}_{3}$ condensed to form clouds (e.g., Lewis 1969; Atreya et al. 1999). This paper primarily concerns the photochemical processes above the clouds, with $\mathrm{H}_{2} \mathrm{O}, \mathrm{CH}_{4}, \mathrm{NH}_{3}$, and $\mathrm{H}_{2} \mathrm{~S}$ as the feedstock.

Past work on the atmospheric photochemistry of lowtemperature and gas-rich planets in the exoplanet context is rare. Moses et al. (2016) studied the thermochemistry and photochemistry in directly imaged young giant planets, and discussed the photochemical production of $\mathrm{CO}_{2}$ and $\mathrm{HCN}$ in 
their atmospheres. Zahnle et al. (2016) showed that sulfur haze can form photochemically in the young Jupiter 51 Eri b, and the level of the sulfur haze would move upward in the atmosphere when the eddy diffusion coefficient increases. Gao et al. (2017) further modeled the effect of the sulfur haze on the reflected starlight spectra of widely separated giant planets. Here, we systematically study the atmospheric photochemistry of $\mathrm{H}_{2} \mathrm{O}, \mathrm{CH}_{4}, \mathrm{NH}_{3}$, and $\mathrm{H}_{2} \mathrm{~S}$ in low-temperature exoplanetary atmospheres and model the abundance of the photochemical gases to guide the future observations of temperate/cold and gas-rich exoplanets.

The paper is organized as follows: Section 2 describes the models used in this study; Section 3 presents the results in terms of the main behaviors of atmospheric chemistry, key photochemical mechanisms, and the corresponding spectral features in transmission and reflected starlight; Section 4 discusses the prospect to detect photochemical gases in temperate and gas-rich exoplanets and potential areas of further development; and Section 5 summarizes the key findings of this study.

\section{Methods}

\subsection{Atmospheric Structure Model}

We use the atmospheric structure and cloud formation model in $\mathrm{Hu}$ (2019) to simulate the pressure-temperature profile and potential gas depletion by condensation in temperate and cold exoplanets.

We have updated the model with a routine to compute the condensation of the $\mathrm{NH}_{4} \mathrm{SH}$ cloud, in a way similar to that of the equilibrium cloud condensation model of Atreya \& Romani (1985). In short, we compare the products of the partial pressure of $\mathrm{NH}_{3}$ and $\mathrm{H}_{2} \mathrm{~S}$ with the equilibrium constant of the reaction that produces an $\mathrm{NH}_{4} \mathrm{SH}$ solid (Lewis 1969), and partition the $\mathrm{NH}_{3}$ and $\mathrm{H}_{2} \mathrm{~S}$ in excess to form the $\mathrm{NH}_{4} \mathrm{SH}$ solid cloud in each atmospheric layer. We have verified that the resulting $\mathrm{NH}_{4} \mathrm{SH}$ cloud density and pressure level is consistent with those of the previously published models when applied to a Jupiter-like planet (e.g., Atreya et al. 1999).

Another update is that the model now traces the concentration of $\mathrm{NH}_{3}$ in liquid-water cloud droplets when applicable. The model of $\mathrm{Hu}$ (2019) has included the dissolution of $\mathrm{NH}_{3}$ in the liquid-water droplets. By additionally tracing the concentration of $\mathrm{NH}_{3}$ in droplets, we have now taken into account the non-ideal effects when the $\mathrm{NH}_{3}$ solution is non-dilute. When the mass ratio between $\mathrm{NH}_{3}$ and $\mathrm{H}_{2} \mathrm{O}$ in the droplet is $>0.05$, we replace Henry's law with the vapor pressure of $\mathrm{NH}_{3}$ in equilibrium with the solution (Perry \& Green 2007). The latter merges the solubility in the Henry's law regime to that in the Raoult's law regime smoothly. We also apply the vapor pressure of $\mathrm{H}_{2} \mathrm{O}$ in equilibrium with the solution, which can be substantially smaller than that with pure water when the solution is non-dilute (i.e., Raoult's law). While the impact of these processes on the overall atmospheric composition of the planets studied in this paper-planets warmer than Jupiter-is small, these processes may control the mixing ratio of $\mathrm{H}_{2} \mathrm{O}$ and $\mathrm{NH}_{3}$ in the atmospheres of even colder planets (De Pater et al. 1989; Romani et al. 1989).

\subsection{Atmospheric Photochemical Model}

We use the general-purpose photochemical model in $\mathrm{Hu}$ et al. $(2012,2013)$ to simulate the photochemical products in the middle atmospheres of temperate and cold exoplanets. The photochemical model includes a carbon chemistry network and a nitrogen chemistry network and their interactions ( $\mathrm{Hu}$ et al. 2012). The photochemical model also includes a sulfur chemistry network and calculates the formation of $\mathrm{H}_{2} \mathrm{SO}_{4}$ and $\mathrm{S}_{8}$ aerosols when applicable (Hu et al. 2013).

We have made several updates to the original reaction network (Hu et al. 2012), and they are listed in Table 1. We have checked the main reactions that produce, remove, and exchange $\mathrm{C}_{1}$ and $\mathrm{C}_{2}$ hydrocarbons in the Jovian atmosphere (Gladstone et al. 1996; Moses et al. 2005) and updated rate constants when more recent values in the relevant temperature range are available in the NIST Chemical Kinetics Database. We have added low-pressure or high-pressure rate constants for three-body reactions if any of them were missing in the original reaction rate list. Certain reactions important for the hydrocarbon chemistry do not have a directly usable rate constant expression in the NIST database; rather, their rates are fitted on experimental data or estimated by Moses et al. (2005). We have also added several reactions that involve $\mathrm{NH}$ because it may be produced by $\mathrm{NH}_{3}$ photodissociation, and updated the rate constant of an important reaction $\mathrm{NH}_{2}+\mathrm{CH}_{4} \rightarrow \mathrm{NH}_{3}+\mathrm{CH}_{3}$ to the latest calculated value. Lastly, we have removed two reactions that were incorrectly included, $\mathrm{CH}_{4}+\mathrm{C}_{2} \mathrm{H}_{2} \rightarrow$ $\mathrm{C}_{2} \mathrm{H}_{3}+\mathrm{CH}_{3}$ and $\mathrm{C}_{2} \mathrm{H}_{6}+\mathrm{C}_{2} \mathrm{H}_{2} \rightarrow \mathrm{C}_{2} \mathrm{H}_{3}+\mathrm{C}_{2} \mathrm{H}_{5}$, because the reactant should have been $\mathrm{CH}_{2}=\mathrm{C}$.

The photochemical model is applied to the "stratosphere" of the atmosphere, where the "tropopause" is defined as the pressure level at which the temperature profile becomes adiabatic. We define the lower boundary of the model as the pressure level 10-fold greater than the tropopause pressure, and thus include a section of the "troposphere" in the model. These choices are customary in photochemical studies of giant planets' atmospheres (e.g., Gladstone et al. 1996), and reasonable because the photochemical products in the stratosphere (and above the condensation clouds) are the objective of the study. Including a section of the troposphere makes sure that the results do not strongly depend on the lower boundary conditions assumed.

We apply fixed mixing ratios as the lower boundary conditions for $\mathrm{H}_{2}, \mathrm{He}, \mathrm{H}_{2} \mathrm{O}, \mathrm{CH}_{4}, \mathrm{NH}_{3}$, and when applicable, $\mathrm{H}_{2} \mathrm{~S}$ according to the assumed elemental abundance. When interior sources of $\mathrm{CO}, \mathrm{CO}_{2}$, and $\mathrm{N}_{2}$ are included in some scenarios (see Section 2.4 for details), fixed mixing ratios are also applied to these gases at the lower boundary. We assume that all other species can move across the lower boundary (i.e., dry deposition when the lower boundary is a surface in terrestrial planet models) at a velocity of $K_{\mathrm{zz}} / H$, where $K_{\mathrm{zz}}$ is the eddy diffusion coefficient and $H$ is the scale height. This velocity is the upper limit of the true diffusion velocity, which could be damped by the gradient of the mixing ratio (Gladstone et al. 1996); however, the velocity only matters for long-lived species (e.g., $\mathrm{C}_{2} \mathrm{H}_{6}$ in Jupiter). Our choice of lower boundary conditions thus results in conservative estimates of the abundance of long-lived photochemical gases.

The upper boundary is assumed to be at $10^{-4} \mathrm{~Pa}$, i.e., small enough so that the peaks of photodissociation of all species are well within the modeled atmosphere. Following Gladstone et al. (1996), we assume a zero-flux boundary condition for all species except for $\mathrm{H}$, for which we include a downward flux of $4 \times 10^{9} \mathrm{~cm}^{-2} \mathrm{~s}^{-1}$ (Waite et al. 1983) to account for ionospheric processes that produce $\mathrm{H}$. This influx of $\mathrm{H}$ was calculated for 
Table 1

Reactions and Rate Constants Updated with Respect to Hu et al. (2012)

\begin{tabular}{|c|c|c|c|}
\hline Reaction & Rate & Reason for Update & Source \\
\hline $\mathrm{H}+\mathrm{C}_{2} \mathrm{H}_{3} \rightarrow \mathrm{C}_{2} \mathrm{H}_{2}+\mathrm{H}_{2}$ & $1.2 \times 10^{-12} T^{0.5}$ & Revise rate & Moses et al. (2005) \\
\hline $\mathrm{H}+\mathrm{C}_{2} \mathrm{H}_{4} \rightarrow \mathrm{C}_{2} \mathrm{H}_{3}+\mathrm{H}_{2}$ & $5.0 \times 10^{-12}(T / 298)^{1.93} \exp (-6520 / T)$ & Revise rate & NIST \\
\hline $\mathrm{H}+\mathrm{C}_{2} \mathrm{H}_{5} \rightarrow 2 \mathrm{CH}_{3}$ & $1.25 \times 10^{-10}$ & Revise rate & NIST \\
\hline $\mathrm{CH}+\mathrm{CH}_{4} \rightarrow \mathrm{C}_{2} \mathrm{H}_{4}+\mathrm{H}$ & $\begin{aligned} & 9.1 \times 10^{-11}(T / 298)^{-0.9}(T>295 \mathrm{~K}) \\
& 1.06 \times 10^{-10}(T / 298)^{-1.04} \exp (-36 / T)(T \leqslant 295 \mathrm{~K})\end{aligned}$ & Revise rate & NIST \\
\hline $\mathrm{CH}_{3}+\mathrm{H}_{2} \rightarrow \mathrm{CH}_{4}+\mathrm{H}$ & $2.31 \times 10^{-14}(T / 298)^{2.24} \exp (-3220.0 / T)$ & Revise rate & NIST \\
\hline $\mathrm{C}_{2} \mathrm{H}+\mathrm{CH}_{4} \rightarrow \mathrm{C}_{2} \mathrm{H}_{2}+\mathrm{CH}_{3}$ & $1.2 \times 10^{-11} \exp (-490.7 / T)$ & Revise rate & NIST \\
\hline $\mathrm{C}_{2} \mathrm{H}+\mathrm{C}_{2} \mathrm{H}_{6} \rightarrow \mathrm{C}_{2} \mathrm{H}_{2}+\mathrm{C}_{2} \mathrm{H}_{5}$ & $2.58 \times 10^{-11}(T / 298)^{0.54} \exp (180 / T)$ & Revise rate & NIST \\
\hline $\mathrm{C}_{2} \mathrm{H}_{3}+\mathrm{H}_{2} \rightarrow \mathrm{C}_{2} \mathrm{H}_{4}+\mathrm{H}$ & $3.39 \times 10^{-14}(T / 298)^{2.56} \exp (-2530.5 / T)$ & Revise rate & NIST \\
\hline $\mathrm{C}_{2} \mathrm{H}_{3}+\mathrm{C}_{2} \mathrm{H}_{5} \rightarrow 2 \mathrm{C}_{2} \mathrm{H}_{4}$ & $8.0 \times 10^{-13}$ & Revise rate & Moses et al. (2005) \\
\hline $\mathrm{C}_{2} \mathrm{H}_{3}+\mathrm{C}_{2} \mathrm{H}_{5} \rightarrow \mathrm{C}_{2} \mathrm{H}_{2}+\mathrm{C}_{2} \mathrm{H}_{6}$ & $8.0 \times 10^{-13}$ & Revise rate & Moses et al. (2005) \\
\hline $\mathrm{C}_{2} \mathrm{H}_{5}+\mathrm{C}_{2} \mathrm{H}_{5} \rightarrow \mathrm{C}_{2} \mathrm{H}_{6}+\mathrm{C}_{2} \mathrm{H}_{4}$ & $2.4 \times 10^{-12}$ & Revise rate & NIST \\
\hline $\mathrm{NH}+\mathrm{NH} \rightarrow \mathrm{N}_{2} \mathrm{H}_{2}$ & $8.47 \times 10^{-11}(T / 298)^{-0.04} \exp (80.6 / T)$ & Add reaction & NIST \\
\hline $\mathrm{NH}+\mathrm{NH}_{2} \rightarrow \mathrm{N}_{2} \mathrm{H}_{2}+\mathrm{H}$ & $1.5 \times 10^{-10}(T / 298)^{-0.27} \exp (38.5 / T)$ & Add reaction & NIST \\
\hline $\mathrm{NH}+\mathrm{CH}_{4} \rightarrow \mathrm{NH}_{2}+\mathrm{CH}_{3}$ & $1.49 \times 10^{-10} \exp (-10,103 / T)$ & Add reaction & NIST \\
\hline $\mathrm{NH}+\mathrm{C}_{2} \mathrm{H}_{6} \rightarrow \mathrm{NH}_{2}+\mathrm{C}_{2} \mathrm{H}_{5}$ & $1.16 \times 10^{-10} \exp (-8420.3 / T)$ & Add reaction & NIST \\
\hline $\mathrm{NH}+\mathrm{OH} \rightarrow \mathrm{NH}_{2}+\mathrm{O}$ & $2.94 \times 10^{-12}(T / 298)^{0.1} \exp (-5800 / T)$ & Revise rate & NIST \\
\hline $\mathrm{NH}_{2}+\mathrm{CH}_{4} \rightarrow \mathrm{NH}_{3}+\mathrm{CH}_{3}$ & $5.75 \times 10^{-11} \exp (-6952 / T)$ & Revise rate & NIST \\
\hline $\mathrm{H}+\mathrm{H} \stackrel{M}{\rightarrow} \mathrm{H}_{2}$ & $k_{0}=\min \left(8.85 \times 10^{-33}(T / 298)^{-0.6}, 1.0 \times 10^{-32}\right)$ & Revise $k_{0}$; & NIST \\
\hline $\mathrm{H}+\mathrm{CH}_{3} \stackrel{M}{\rightarrow} \mathrm{CH}_{4}$ & $\begin{array}{c}k_{\infty}=1.0 \times 10^{-11} \\
k_{0}=6.0 \times 10^{-29} \max (T / 298,1.0)^{-1.8} \\
k_{\infty}=1.92 \times 10^{-8}\left(\max (T, 110)^{-0.5} \exp (-400 / \max (T, 110))\right. \\
F_{c}=0.3+0.58 \exp (-T / 800)\end{array}$ & $\begin{array}{c}\text { Add } k_{\infty} \\
\text { Revise } k_{0} \text { at } T \leqslant 298 \mathrm{~K} \\
\text { Add } k_{\infty}\end{array}$ & $\begin{array}{l}\text { Moses et al. (2005) } \\
\text { NIST; } \\
\text { Moses et al. (2005) }\end{array}$ \\
\hline $\mathrm{H}+\mathrm{C}_{2} \mathrm{H} \stackrel{M}{\rightarrow} \mathrm{C}_{2} \mathrm{H}_{2}$ & $\begin{array}{c}k_{0}=1.26 \times 10^{-18} T^{-3.1} \exp (-721 / T) \\
k_{\infty}=3.0 \times 10^{-10}\end{array}$ & Add $k_{0}$ & Moses et al. (2005) \\
\hline $\mathrm{H}+\mathrm{C}_{2} \mathrm{H}_{2} \stackrel{M}{\rightarrow} \mathrm{C}_{2} \mathrm{H}_{3}$ & $\begin{array}{c}k_{0}=3.31 \times 10^{-30} \exp (-740 / T) \\
k_{\infty}=1.4 \times 10^{-11} \exp (-1300 / T) \\
F_{c}=0.44\end{array}$ & Add $k_{\infty}$ & NIST \\
\hline $\mathrm{H}+\mathrm{C}_{2} \mathrm{H}_{3} \stackrel{M}{\rightarrow} \mathrm{C}_{2} \mathrm{H}_{4}$ & $\begin{array}{c}k_{0}=2.3 \times 10^{-24} T^{-1} \\
k_{\propto}=1.8 \times 10^{-10}\end{array}$ & Add $k_{0}$ & Moses et al. (2005) \\
\hline $\mathrm{H}+\mathrm{C}_{2} \mathrm{H}_{4} \stackrel{M}{\rightarrow} \mathrm{C}_{2} \mathrm{H}_{5}$ & $\begin{array}{c}k_{\infty}=1.8 \times 10^{-10} \\
k_{0}=\max \left(1.3 \times 10^{-29} \exp (-380 / T), 3.7 \times 10^{-30}\right) \\
k_{\infty}=6.6 \times 10^{-15} T^{1.28} \exp (-650 / T) \\
F_{c}=0.24 \exp (-T / 40)+0.76 \exp (-T / 1025)\end{array}$ & $\begin{array}{c}\text { Revise } k_{\infty} \\
\text { Revise } k_{0} \text { at } T \leqslant 300 \mathrm{~K} \\
\text { Add } k_{\infty}\end{array}$ & $\begin{array}{c}\text { NIST; } \\
\text { Moses et al. (2005) }\end{array}$ \\
\hline $\mathrm{H}+\mathrm{C}_{2} \mathrm{H}_{5} \stackrel{M}{\rightarrow} \mathrm{C}_{2} \mathrm{H}_{6}$ & $\begin{array}{c}k_{0}=4.0 \times 10^{-19} T^{-3} \exp (-600 / T)(T>200 \mathrm{~K}) \\
k_{0}=2.49 \times 10^{-27}(T \leqslant 200 \mathrm{~K}) \\
k_{\infty}=2.0 \times 10^{-10}\end{array}$ & Revise $k_{0}$ & Moses et al. (2005) \\
\hline $\mathrm{C}+\mathrm{H}_{2} \stackrel{M}{\rightarrow} \mathrm{CH}_{2}$ & $\begin{array}{c}k_{0}=6.89 \times 10^{-32} \\
k_{\infty}=2.06 \times 10^{-11} \exp (-57 / T)\end{array}$ & Add $k_{\infty}$ & NIST \\
\hline $\mathrm{CH}+\mathrm{H}_{2} \stackrel{M}{\rightarrow} \mathrm{CH}_{3}$ & $\begin{aligned} k_{0} & =9.0 \times 10^{-31} \exp (550 / T) \\
k_{\infty} & =2.01 \times 10^{-10}(T / 298)^{0.15}\end{aligned}$ & Revise $k_{0}$ and $k_{\infty}$ & $\begin{array}{c}\text { NIST } \\
\text { Moses et al. (2005) }\end{array}$ \\
\hline $\mathrm{CH}_{3}+\mathrm{CH}_{3} \stackrel{M}{\rightarrow} \mathrm{C}_{2} \mathrm{H}_{6}$ & $\begin{array}{c}k_{0}=1.68 \times 10^{-24}(T / 298)^{-7} \exp (-1390 / T)(T>300 \mathrm{~K}) \\
k_{0}=6.15 \times 10^{-18} T^{-3.5}(T \leqslant 300 \mathrm{~K}) \\
k_{\infty}=1.12 \times 10^{-9} T^{-0.5} \exp (-25 / T) \\
F_{c}=0.62 \exp (-T / 1180)+0.38 \exp (-T / 73)\end{array}$ & $\begin{array}{c}\text { Revise } k_{0} \text { at } T \leqslant 300 \mathrm{~K} \\
\text { Add } k_{\infty}\end{array}$ & $\begin{array}{l}\text { NIST; } \\
\text { Moses et al. (2005) }\end{array}$ \\
\hline
\end{tabular}

Note. The rate constants of two-body reactions and the high-pressure limiting rate constants of three-body reactions $\left(k_{\infty}\right)$ have a unit of $\mathrm{cm}^{3} \mathrm{molecule}{ }^{-1} \mathrm{~s}^{-1}$, and the low-pressure limiting rate constants of three-body reactions $\left(k_{0}\right)$ have a unit of $\mathrm{cm}^{6}$ molecule $\mathrm{e}^{-2} \mathrm{~s}^{-1}$. The rates of three-body reactions are $k_{0} k_{\infty}[M] /\left(k_{\infty}+k_{0}[M]\right) F_{c}^{\beta}$, where $[M]$ is the number density of the atmosphere, and $\beta=\left(1+\left(\log _{10}\left(k_{0}\left[M / k_{\infty}\right)\right)^{2}\right)^{-1} \cdot F_{c}=0.6\right.$ unless otherwise noted. NIST $=$ NIST Chemical Kinetics Database (http://kinetics.nist.gov).

Jupiter and the actual flux can conceivably be different. The impact of this additional $\mathrm{H}$ is limited to the upper atmosphere and, in most of our cases, is swamped by the $\mathrm{H}$ from the photodissociation of $\mathrm{H}_{2} \mathrm{O}$ (see Section 3.4).

Since the modeled domain of the atmosphere includes the stratosphere and a small section of the upper troposphere, the standard mixing-length scaling (Gierasch \& Conrath 1985) is not applicable to estimate the eddy diffusion coefficient. We instead anchor our choice of the eddy diffusion coefficient on the value in the upper troposphere of Jupiter $\left(\sim 1 \times 10^{3} \mathrm{~cm}^{2}\right.$ $\mathrm{s}^{-1}$, Conrath \& Gierasch 1984) and explore a larger value in the study. Above the tropopause, we assume that mixing is predominantly caused by the breaking of gravity waves and the eddy diffusion coefficient is inversely proportional to the square root of the number density (Lindzen 1981).

Because the pressure range of the photochemical model typically includes the condensation of $\mathrm{NH}_{3}$ and $\mathrm{H}_{2} \mathrm{O}$, we have added a scheme to account for the condensation of $\mathrm{NH}_{3}$ into the 



Figure 1. Jupiter as a test case. The planet modeled is a Jupiter-mass and Jupiter-radius planet at a 5.2 au orbit of a Sun-like star, having an atmospheric metallicity of $3 \times$ solar. (a) The solid line is the pressure-temperature profile adopted from Galileo probe measurements and Cassini CIRS measurements in Jupiter (Seiff et al. 1998; Simon-Miller et al. 2006) and the dashed line is the pressure-temperature profile calculated by the atmospheric structure model. (b) The eddy diffusion coefficient profile adopted in this work. (c) The calculated mixing ratio profiles of $\mathrm{CH}_{4}, \mathrm{NH}_{3}$, and major photochemical products. The solid lines are the results using the measured temperature profile, the dashed lines are the results using the modeled temperature profile (i.e., without the temperature inversion), and the dotted lines are the results using the modeled temperature profile and the photodissociation quantum yield of $\mathrm{C}_{2} \mathrm{H}_{2}$ set to unity (see discussion in Section 2.3). In comparison are the abundance data of major hydrocarbons and HCN in Jupiter's atmosphere, as compiled in Morrissey et al. (1995), Gladstone et al. (1996), Davis et al. (1997), Yelle et al. (2001), and Moses et al. (2005).

photochemical model, with that for $\mathrm{H}_{2} \mathrm{O}$ already included in the model of $\mathrm{Hu}$ et al. (2012). In addition, we have added the schemes of condensation for $\mathrm{N}_{2} \mathrm{H}_{4}$ and $\mathrm{HCN}$, the two main photochemical gases expected to condense in Jupiter's upper troposphere (e.g., Atreya et al. 1977; Moses et al. 2010). The low-temperature vapor pressures of $\mathrm{N}_{2} \mathrm{H}_{4}$ and $\mathrm{HCN}$ are adopted from Atreya et al. (1977) and Krasnopolsky (2009), respectively. As such, these gases are treated in the photochemical model and their production and removal paths including chemical reactions and condensation are selfconsistently computed. This is important because, for example, $\mathrm{NH}_{3}$ above the clouds in Jupiter is expected to be completely removed by photodissociation and converted to $\mathrm{N}_{2} \mathrm{H}_{4}$ and $\mathrm{N}_{2}$, followed by condensation and transport to the deep atmosphere (Strobel 1973; Atreya et al. 1977; Kaye \& Strobel 1983a, 1983b; Moses et al. 2010). As we will show in Section 3, the condensation of $\mathrm{N}_{2} \mathrm{H}_{4}$ and $\mathrm{HCN}$ limits their abundance in the middle atmosphere of cold planets like Kepler-167 e. For $\mathrm{H}_{2} \mathrm{~S}$, we make a binary choice: if the cloud model indicates $\mathrm{NH}_{4} \mathrm{SH}$ formation, we remove sulfur chemistry from the model, because $\mathrm{NH}_{4} \mathrm{SH}$ should completely sequester $\mathrm{H}_{2} \mathrm{~S}$ (Atreya \& Romani 1985); and we include the sulfur chemistry if $\mathrm{NH}_{4} \mathrm{SH}$ cloud is not formed. This simplifies the calculations of sulfur photochemistry and is broadly valid when N/S $>1$ in the bulk atmosphere.

We calculate the cross sections and single scattering albedo of ammonia and water cloud particles using their optical properties (Palmer \& Williams 1974; Martonchik et al. 1984) and the radiative properties of the sulfur haze particles in the same way as $\mathrm{Hu}$ et al. (2013). $\mathrm{NH}_{4} \mathrm{SH}$ and $\mathrm{HCN}$ condensates are treated the same way as $\mathrm{NH}_{3}$ clouds. $\mathrm{N}_{2} \mathrm{H}_{4}$ condensates have a very low abundance in all models and do not contribute significantly to the opacity. Thus, our model includes the absorption and scattering of cloud and haze particles when calculating the radiation field that drives photochemical reactions in the atmosphere.

\subsection{Jupiter as a Test Case}

As a test case, we have applied the coupled cloud condensation and photochemical model to a Jupiter-like planet and compared the results with the measured gas abundance in Jupiter and previous models of Jupiter's stratospheric composition (Atreya et al. 1977; Kaye \& Strobel 1983a, 1983b; Gladstone et al. 1996; Moses et al. 2005, 2010). Figure 1 shows the pressure-temperature profile, eddy diffusion coefficient, and the mixing ratios of $\mathrm{CH}_{4}, \mathrm{NH}_{3}$, and major photochemical gases of the test case. The atmospheric structure model adequately predicts the tropospheric temperature profile and the pressure level of the tropopause, but it cannot generate a temperature inversion in the middle atmosphere (Figure 1, panel (a)). We have run the photochemical model with the pressure-temperature profile measured in Jupiter and the modeled pressure-temperature profile (i.e., without the temperature inversion) to see how much the photochemical gas mixing ratios change.

We find that the photochemical model can predict the mixing ratios of $\mathrm{C}_{2} \mathrm{H}_{6}, \mathrm{C}_{2} \mathrm{H}_{2}$, and $\mathrm{C}_{2} \mathrm{H}_{4}$ measured in Jupiter's stratosphere, and the modeled profile of $\mathrm{HCN}$ is consistent with the upper limit in Jupiter's upper troposphere when the measured pressure-temperature profile is adopted (Figure 1, panel (c)). The only exception is the $\mathrm{C}_{2} \mathrm{H}_{2}$ mixing ratio at 
$\sim 1 \mathrm{~Pa}$, where the modeled mixing ratio is greater than the measured value by $2 \sigma \sim 3 \sigma$. This less-than-perfect performance may be due to the lack of $\mathrm{C}_{3}, \mathrm{C}_{4}$, and higher hydrocarbons in our reaction network. For example, Moses et al. (2005) was able to fit the $\mathrm{C}_{2} \mathrm{H}_{2}$ mixing ratio at $\sim 1 \mathrm{~Pa}$, together with other mixing ratio constraints, with a more complete hydrocarbon reaction network and specific choices in the eddy diffusion coefficient profiles for Jupiter's stratosphere. In terms of nitrogen photochemistry, our photochemical model finds that $\mathrm{NH}_{3}$ is depleted by photodissociation to the cloud deck, and the vast majority of the net photochemical removal of $\mathrm{NH}_{3}$ becomes $\mathrm{N}_{2} \mathrm{H}_{4}$ and then condenses out. A small fraction becomes $\mathrm{N}_{2}$ and $\mathrm{HCN}$. The abundance of $\mathrm{HCN}$ is low $\left(\sim 10^{-9}\right)$ in the troposphere due to the photolysis of $\mathrm{NH}_{3}$ and $\mathrm{CH}_{4}$ occurring at well separated pressure levels, and is limited by the cold trap near the tropopause (Figure 1). These behaviors are qualitatively similar to the past models of Jupiter's nitrogen photochemistry (Atreya et al. 1977; Kaye \& Strobel 1983a, 1983b; Moses et al. 2010).

Figure 1 also indicates that adopting the modeled pressuretemperature profile that does not have a stratosphere, while preserving the overall behavior of the atmospheric photochemistry, would underpredict the mixing ratios of $\mathrm{C}_{2} \mathrm{H}_{6}$ and $\mathrm{C}_{2} \mathrm{H}_{2}$ by approximately half an order of magnitude. We use the atmospheric structure model in this study for speedy exploration of the main photochemical behavior, and one should keep this context in mind when interpreting the results shown in Section 3.

Another interesting point to make is that the quantum yield of $\mathrm{H}$ in the photodissociation $\mathrm{C}_{2} \mathrm{H}_{2}$ has been convincingly measured to be $100 \%$ by recent experiments (Läuter et al. 2002). When producing the models shown as the solid and dashed lines in Figure 1, panel c, we have applied a quantum yield of $16 \%$ so that the top-of-atmosphere rate of $\mathrm{C}_{2} \mathrm{H}_{2}+h \nu \rightarrow \mathrm{C}_{2} \mathrm{H}+\mathrm{H}$ would match with the models of Gladstone et al. (1996) and Moses et al. (2005). Revising the quantum yield to $100 \%$, as shown by the dotted lines in Figure 1, panel c, slightly reduces the steady-state mixing ratio of $\mathrm{C}_{2} \mathrm{H}_{6}$ and reduces the mixing ratio of $\mathrm{C}_{2} \mathrm{H}_{2}$ and $\mathrm{C}_{2} \mathrm{H}_{4}$ by a factor of $\sim 5$ in the lower stratosphere $\left(\sim 10^{3} \mathrm{~Pa}\right)$. The photodissociation of $\mathrm{C}_{2} \mathrm{H}_{2}$ is the main source of $\mathrm{H}$ in the lower stratosphere (e.g., Gladstone et al. 1996) and thus its quantum yield is important for the hydrocarbon chemistry in the lower stratosphere. However, a quantum yield of $100 \%$ would result in poor fits to the measured mixing ratios of $\mathrm{C}_{2} \mathrm{H}_{2}$ and $\mathrm{C}_{2} \mathrm{H}_{4}$, and this potential discrepancy suggests that additional consideration of the atmospheric photochemistry of Jupiter might be warranted. We adopt the quantum yield of $100 \%$ in the subsequent models.

\subsection{Planet Scenarios}

We use the temperate sub-Neptune K2-18 b as a representative case of temperate and gas-rich planets around $\mathrm{M}$ dwarf stars, and use the gas giants $\mathrm{PH} 2 \mathrm{~b}$ and Kepler-167e as the representative cases of temperate and cold planets around $\mathrm{G}$ and $\mathrm{K}$ stars (Table 2). The results for K2-18 b are generally applicable to temperate (mini-)Neptunes of $\mathrm{M}$ dwarf stars such as the recently detected TOI- $1231 \mathrm{~b}$. For K2-18 b, the interior structures, thermochemical abundances, and atmospheric circulation patterns have been studied (Benneke et al. 2019; Madhusudhan et al. 2020; Piette \& Madhusudhan 2020; Blain et al. 2021; Charnay et al. 2021), but the effects of atmospheric

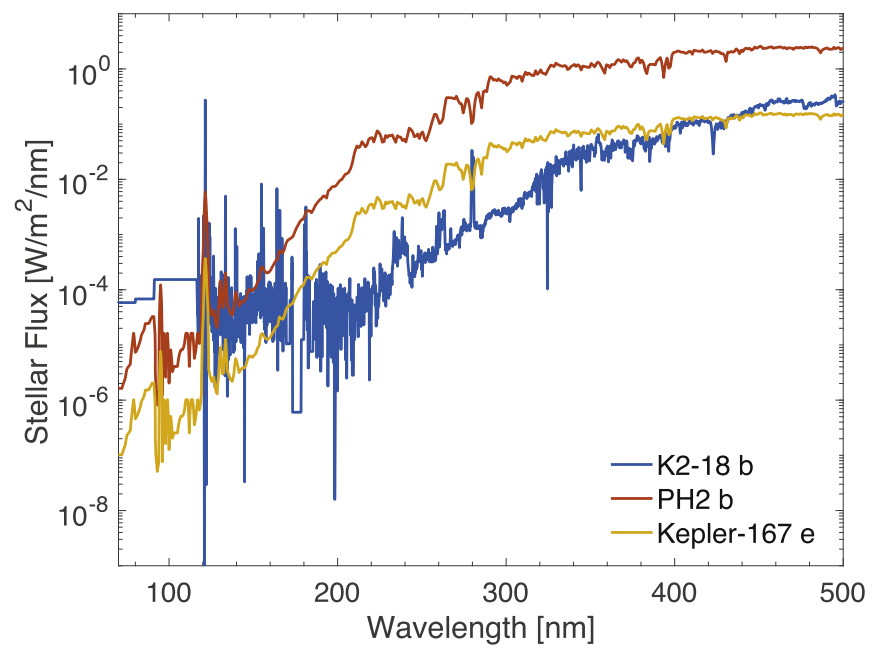

Figure 2. Incident stellar flux at the top of the atmospheres adopted in this study.

Table 2

Planetary Parameters Adopted in this Study

\begin{tabular}{lccc}
\hline \hline Planet & K2-18 b & PH2 b & Kepler-167 e \\
\hline$M_{p}\left(M_{\oplus}\right)$ & $8.63^{\mathrm{a}}$ & $\mathrm{N} / \mathrm{A}$ & $\mathrm{N} / \mathrm{A}$ \\
$R_{p}\left(R_{\oplus}\right)$ & $2.61^{\mathrm{b}}$ & $9.40^{\mathrm{c}}$ & $9.96^{\mathrm{c}}$ \\
Insolation (Earth) & $1.0^{\mathrm{a}}$ & $1.2^{\mathrm{d}}$ & $0.075^{\mathrm{e}}$ \\
Stellar Type & $\mathrm{M}$ & $\mathrm{G}$ & $\mathrm{K}$ \\
\hline
\end{tabular}

Notes.

a Benneke et al. (2019)

${ }^{\mathrm{b}}$ Cloutier et al. (2019).

${ }^{\mathrm{c}}$ Berger et al. (2018).

${ }^{\mathrm{d}}$ Wang et al. (2013).

${ }^{\mathrm{e}}$ Kipping et al. (2016).

photochemistry remain to be studied. Kepler-167 e is considered a "cold" exoplanet because it only receives stellar irradiation $7.5 \%$ of Earth's. The equilibrium cloud condensation model would predict $\mathrm{NH}_{3}$ to condense in its atmosphere and form the uppermost cloud deck, below which $\mathrm{NH}_{4} \mathrm{SH}$ solids form and scavenge sulfur from the above-cloud atmosphere. In the atmospheres of $\mathrm{K} 2-18 \mathrm{~b}$ and $\mathrm{PH} 2 \mathrm{~b}$, only $\mathrm{H}_{2} \mathrm{O}$ is expected to condense and forms the cloud deck-and thus the physical distinction between "temperate" and "cold."

The UV spectrum of K2-18 has not been measured and so we adopt that of GJ 176, a similar M dwarf star with the UV spectrum measured in the MUSCLES survey (France et al. 2016). The reconstructed Ly $\alpha$ flux of GJ 176 is similar to the measured flux of K2-18 (dos Santos et al. 2020). We adopt the UV spectrum of the Sun for the models of PH2 b and Kepler167 e, even though Kepler- 167 is a K star. Figure 2 shows the incident stellar flux at the top of the atmospheres adopted in this study. K2-18 b, while having a similar total irradiation to that of $\mathrm{PH} 2 \mathrm{~b}$, receives considerably less irradiation in the nearultraviolet.

For these planets, we simulate $\mathrm{H}_{2}$-dominated atmospheres having 1-100 $\times$ solar metallicities. The higher-than-solar metallicity scenario may be particularly interesting for sub-Neptunes like K2-18 b because of a proposed mass-metallicity relationship that posits a less massive planet should have a higher metallicity (Thorngren et al. 2016). For PH2 b and Kepler-167 


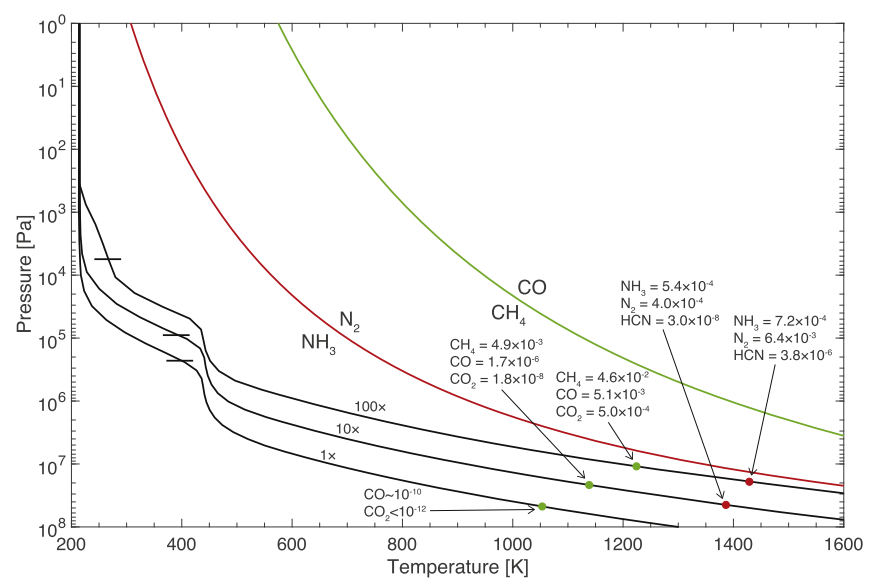

Figure 3. Pressure-temperature profiles of the temperate sub-Neptune K2-18 b for varied atmospheric metallicities and an internal heat flux of $T_{\text {int }}=60 \mathrm{~K}$ (similar to Neptune). The short horizontal bars show the lower boundary of the photochemical model (i.e., the pressure level 10-fold greater than the tropopause pressure). The green and red lines show the equal-abundance boundaries for major carbon and nitrogen gases in a solar metallicity gas in thermochemical equilibrium, and the green and red dots show the expected quench point for $\mathrm{CO}$ and that for $\mathrm{N}_{2}$ respectively. The equilibrium mixing ratios of major $\mathrm{C}$ and $\mathrm{N}$ molecules at the respective quench points are shown.

e, we assume as fiducial values a surface gravity of $25 \mathrm{~m} \mathrm{~s}^{-2}$ and an internal heat flux that corresponds to $T_{\mathrm{int}}=100 \mathrm{~K}$, similar to the parameters of Jupiter. Changing the surface gravity to $100 \mathrm{~m} \mathrm{~s}^{-2}$ results in slightly different cloud pressures and above-cloud abundances of gases on these planets, but does not change the qualitative behaviors of the atmospheric chemistry. For K2-18 b we assume an internal heat flux that corresponds to $T_{\text {int }}=60 \mathrm{~K}$, similar to that of Neptune.

In the standard models, we assume that the dominant $\mathrm{O}, \mathrm{C}$, $\mathrm{N}$, and $\mathrm{S}$ species are $\mathrm{H}_{2} \mathrm{O}, \mathrm{CH}_{4}, \mathrm{NH}_{3}$, and $\mathrm{H}_{2} \mathrm{~S}$ at the base of the photochemical domain. Gases and aerosols produced in the photochemical domain can be transported through the lower boundary, and thus the standard model setup implicitly assumes that thermochemical recycling in the deep troposphere effectively recycles the photochemical products into $\mathrm{H}_{2} \mathrm{O}, \mathrm{CH}_{4}$, $\mathrm{NH}_{3}$, and $\mathrm{H}_{2} \mathrm{~S}$. Here, we quantitatively assess how realistic this assumption is based on the quench-point theory (e.g., Visscher \& Moses 2011; Moses et al. 2013; Hu \& Seager 2014; Zahnle \& Marley 2014; Tsai et al. 2018). In that theory, the "quench point" is defined as the pressure level where the chemical lifetime of a gas equals the vertical mixing timescale (typically at the pressure of $10^{7} \mathrm{~Pa}$ or higher). The gas is close to thermochemical equilibrium at the quench point, and its mixing ratio is carried to the atmosphere above the quench point by vertical mixing.

Figures 3-5 show the pressure-temperature profiles of the three planets calculated by the atmospheric structure model, and the mixing ratios of major $\mathrm{C}$ and $\mathrm{N}$ molecules at the respective quench points. We adopt the chemical lifetime of the $\mathrm{CO} \longleftrightarrow \mathrm{CH}_{4}$ and $\mathrm{N}_{2} \longleftrightarrow \mathrm{NH}_{3}$ conversions from Zahnle \& Marley (2014) and estimate the eddy diffusion coefficient in the deep troposphere using the mixing-length theory in Visscher et al. (2010). The eddy diffusion coefficient depends on the assumed internal heat flux and has a typical value of $\sim 10^{4} \mathrm{~m}^{2} \mathrm{~s}^{-1}$ at the pressure of $10^{6}-10^{8} \mathrm{~Pa}$. The quench point of $\mathrm{CO}_{2}$ follows that of $\mathrm{CO}$, and, similarly, that of $\mathrm{HCN}$ occurs at a similar pressure and temperature as $\mathrm{N}_{2}$ (Zahnle \& Marley 2014; Tsai et al. 2018). The mixing ratios of gases at the quench points are



Figure 4. The same as Figure 3 but for the planetary parameters of $\mathrm{PH} 2 \mathrm{~b}$ and an internal heat flux of $T_{\text {int }}=100 \mathrm{~K}$ (similar to Jupiter).

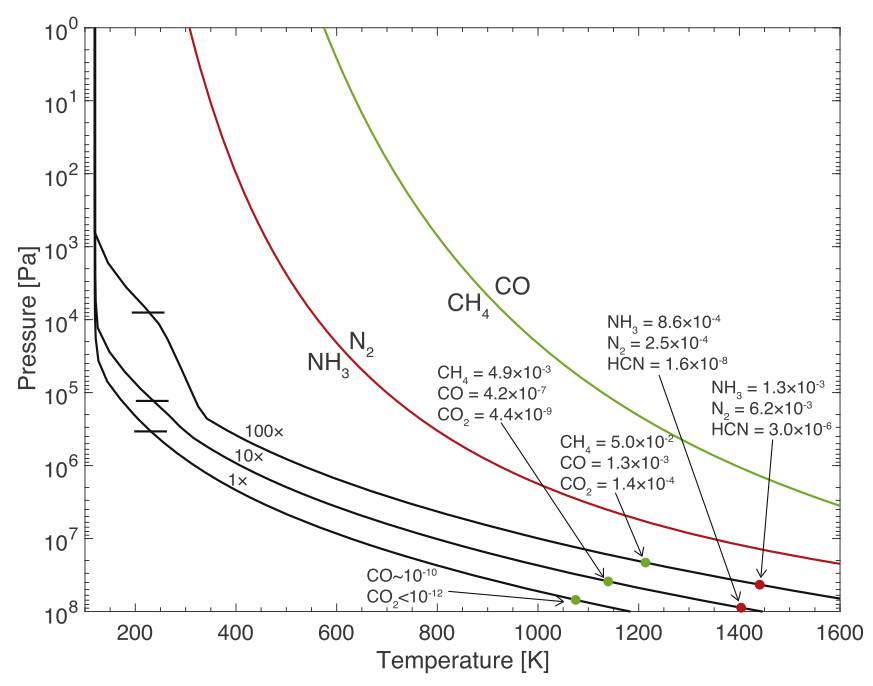

Figure 5. The same as Figure 3 but for the planetary parameters of Kepler$167 \mathrm{e}$ and an internal heat flux of $T_{\mathrm{int}}=100 \mathrm{~K}$ (similar to Jupiter).

calculated using the thermochemical equilibrium model of $\mathrm{Hu}$ \& Seager (2014).

Figures 3-5 show that a solar metallicity atmosphere is likely deep in the $\mathrm{CH}_{4}$ - and $\mathrm{NH}_{3}$-dominated regime at the quench points on all three planets. Specifically, we find the mixing ratio of $\mathrm{CO} \leqslant 10^{-8}$, that of $\mathrm{CO}_{2} \leqslant 10^{-11}$, and the mixing ratio of $\mathrm{NH}_{3}$ greater than that of $\mathrm{N}_{2}$ by $>10$-fold. With $10 \times$ solar metallicity, the atmosphere remains $\mathrm{CH}_{4}$ dominated, but the mixing ratio of $\mathrm{CO}$ transported from the deep troposphere can be on the order of $10^{-6} \sim 10^{-5}$ and thus non-negligible. With the assumed internal heat flux and the modeled strength of deep-tropospheric mixing, the mixing ratio of $\mathrm{N}_{2}$ can be comparable to that of $\mathrm{NH}_{3}$ at the quench point. As $\mathrm{N}_{2}$ does not have strong spectral features and is not a feedstock molecule for photochemistry, the effect of a hot interior would be mostly seen as a reduction of the mixing ratio of $\mathrm{NH}_{3}$. The impact of the hot interior is the most significant in the $100 \times$ solar metallicity atmosphere. Both $\mathrm{CO}$ and $\mathrm{CO}_{2}$ have mixing ratios $>10^{-4}$ at the quench point, and in the hottest case ( $\mathrm{PH} 2 \mathrm{~b}$ ), the mixing ratio $\mathrm{CO}$ is greater than that of $\mathrm{CH}_{4}$. For nitrogen, the 
mixing ratio of $\mathrm{NH}_{3}$ can be reduced by a factor of $10 \sim 100$ at the thermochemical equilibrium in the deep troposphere.

As a general trend, a higher deep-atmosphere temperature favors $\mathrm{CO}, \mathrm{CO}_{2}$, and $\mathrm{N}_{2}$, and reduces the equilibrium abundance of $\mathrm{NH}_{3}$. We have thus run variant models for the $10 \times$ and $100 \times$ solar metallicity cases, and used the mixing ratios of $\mathrm{CH}_{4}, \mathrm{CO}, \mathrm{CO}_{2}, \mathrm{NH}_{3}$, and $\mathrm{N}_{2}$ at the quench points as shown in Figures $3-5$ as the lower boundary conditions. Technically the mixing ratio of deep $\mathrm{H}_{2} \mathrm{O}$ is also affected, but the photochemical models have lower boundaries that are well above the base of the water cloud, and are thus immune to small changes in the input water abundance. Also, we do not fix the lower boundary mixing ratio of $\mathrm{HCN}$ in these models, because the mixing ratio of $\mathrm{HCN}$ at the quench point does not exceed the mixing ratio found by the photochemical models at the lower boundary in any case. We emphasize that specific quantities of the input gas abundance depend on the detailed thermal structure of the interior, which is related to the thermal history of the planet and exogenous factors like tidal heating, as well as the strength of vertical mixing in the interior (Fortney et al. 2020). For example, applying an internal heat flux that corresponds to $T_{\text {int }}=30 \mathrm{~K}$ (similar to Earth) largely restores the $\mathrm{CH}_{4}$ and $\mathrm{NH}_{3}$ dominance for the three planets. While these factors are likely uncertain for many planets to be observed, the standard and variant photochemical models presented in this paper give an account of the range of possible behaviors that manifest in the observable part of the atmosphere.

\section{Results}

\subsection{Main Behaviors of Atmospheric Chemistry}

The abundance profiles of the equilibrium gases $\left(\mathrm{H}_{2} \mathrm{O}, \mathrm{CH}_{4}\right.$, $\mathrm{NH}_{3}$, and $\mathrm{H}_{2} \mathrm{~S}$ ) and their main photochemical products are shown in Figures 6-8. In all models, we find that the main photochemical products are $\mathrm{C}_{2} \mathrm{H}_{6}, \mathrm{C}_{2} \mathrm{H}_{2}, \mathrm{CO}, \mathrm{CO}_{2}, \mathrm{~N}_{2}, \mathrm{HCN}$, $\mathrm{N}_{2} \mathrm{O}$, and elemental sulfur haze, but the abundance of these species and their pressure dependency differ significantly from model to model.

\subsubsection{K2-18 b: a Temperate Planet around an M Star}

For $\mathrm{K} 2-18 \mathrm{~b}$, our model predicts that water condenses to form a cloud at the pressure of $\geqslant 10^{4} \mathrm{~Pa}$ for the solar and $10 \times$ solar cases, and at the pressure of $\sim 10^{3} \mathrm{~Pa}$ for the $100 \times$ solar case. Above the cloud, the mixing ratio of water is depleted by approximately one order of magnitude, but not totally depleted. The pressure of cloud for the $100 \times$ solar abundance case we model is consistent with predictions of a non-gray radiative-equilibrium model and a 3D climate model, but those models do not predict a water cloud for the solar and $10 \times$ solar abundance (Blain et al. 2021; Charnay et al. 2021). Given the small degree of water depletion found in our models, this discrepancy does not lead to substantial errors in the results of the above-cloud photochemistry.

Both $\mathrm{CH}_{4}$ and $\mathrm{H}_{2} \mathrm{O}$ are photodissociated at the pressure of approximately $0.1-1 \mathrm{~Pa}$. The photodissociation results in the formation of $\mathrm{C}_{2} \mathrm{H}_{6}, \mathrm{C}_{2} \mathrm{H}_{2}, \mathrm{CO}$, and $\mathrm{CO}_{2} . \mathrm{C}_{2} \mathrm{H}_{2}$ has a high mixing ratio at the pressure where the photodissociation takes place but is quickly depleted toward higher pressures. In the middle atmosphere $\left(\sim 10-10^{3} \mathrm{~Pa}\right), \mathrm{CO}, \mathrm{CO}_{2}$, and $\mathrm{C}_{2} \mathrm{H}_{6}$ can have a mixing ratio of $\sim 1$ parts-per-million (ppm) for the $100 \times$ solar abundance case, and the mixing ratio of these photochemical gases is $<1 \mathrm{ppm}$ for lower metallicities. When the deep-tropospheric source of $\mathrm{CO}$ and $\mathrm{CO}_{2}$ is applied to the bottom of the photochemical domain, the mixing ratio of $\mathrm{CO}$ at $10^{2} \mathrm{~Pa}$ is $\sim 1 \mathrm{ppm}$ for the $10 \times$ solar cases, but it can reach $\sim 4000 \mathrm{ppm}$ for the $100 \times$ solar case. The mixing ratio of $\mathrm{CO}_{2}$ at $10^{2} \mathrm{~Pa}$ can reach $\sim 500 \mathrm{ppm}$ for the $100 \times$ solar case.

$\mathrm{NH}_{3}$ is photodissociated at the pressure of $1 \sim 10 \mathrm{~Pa}$. The photodissociation results in the formation of $\mathrm{N}_{2}$ and $\mathrm{HCN}$ with similar yields. The mixing ratio of $\mathrm{HCN}$ at $\sim 10^{2} \mathrm{~Pa}$ is $\sim 6,50$, and $500 \mathrm{ppm}$ for the solar, $10 \times$ solar, and $100 \times$ solar abundance cases, respectively. If the mixing ratio of $\mathrm{NH}_{3}$ in the deep troposphere is applied to the bottom of the photochemical domain, the resulting mixing ratio of $\mathrm{HCN}$ does not change significantly in the $10 \times$ solar case but decreases to $\sim 100 \mathrm{ppm}$ in the $100 \times$ solar case.

Lastly, $\mathrm{H}_{2} \mathrm{~S}$ is photodissociated at approximately the same pressure as the water cloud. The photodissociation leads to the formation of elemental sulfur $\left(\mathrm{S}_{8}\right)$ haze, as predicted previously (Zahnle et al. 2016). The haze layer extends to an altitude only slightly higher than the water cloud deck.

\subsubsection{PH2 b: a Temperate Planet around a $G / K$ Star}

$\mathrm{PH} 2 \mathrm{~b}$ has a slightly higher insolation and temperature than $\mathrm{K} 2-18 \mathrm{~b}$, but it receives much more near-ultraviolet irradiation (Figure 2). The water condensation and small degree of depletion above the cloud, as well as the photodissociation of $\mathrm{H}_{2} \mathrm{~S}$ and the location of the sulfur haze layer, are similar to those predicted for $\mathrm{K} 2-18 \mathrm{~b}$.

$\mathrm{CH}_{4}$ is photodissociated at the pressure of $0.1-1 \mathrm{~Pa}$, and $\mathrm{H}_{2} \mathrm{O}$ is photodissociated at $1-10 \mathrm{~Pa}$. The main products of these photodissociations are still $\mathrm{C}_{2} \mathrm{H}_{6}, \mathrm{C}_{2} \mathrm{H}_{2}, \mathrm{CO}$, and $\mathrm{CO}_{2}$. Instead of $\mathrm{CO}$ in the case of $\mathrm{K} 2-18 \mathrm{~b}, \mathrm{CO}_{2}$ is the most abundant photochemical gas in the middle atmosphere $\left(\sim 10-10^{3} \mathrm{~Pa}\right)$, and its mixing ratio is $2-10 \mathrm{ppm}, 5-40 \mathrm{ppm}$, and $40-200 \mathrm{ppm}$ for the solar, $10 \times$ solar, and $100 \times$ solar abundance cases, respectively. The mixing ratio of $\mathrm{CO}$ is less by approximately one order of magnitude, and that of $\mathrm{C}_{2} \mathrm{H}_{6}$ is $\sim 1 \mathrm{ppm}$ for the $100 \times$ solar case and $<1 \mathrm{ppm}$ for lower metallicities.

As a striking difference from the $\mathrm{M}$ star case (K2-18 b), $\mathrm{NH}_{3}$ is fully depleted by photodissociation above the water cloud deck. The mixing ratio of $\mathrm{NH}_{3}$ in the middle atmosphere is minimal. The photodissociation also leads to the formation of $\mathrm{N}_{2}$ and $\mathrm{HCN}$, with $\mathrm{HCN}$ being the most abundant photochemical product. The mixing ratio of $\mathrm{HCN}$ in the middle atmosphere reaches $\sim 100,700$, and $10,000 \mathrm{ppm}$ for the solar, $10 \times$ solar, and $100 \times$ solar abundance cases, respectively.

With a Jupiter-like internal heat flux, the equilibrium chemistry in the deep troposphere may substantially change the chemical composition in the photochemical domain. In the $10 \times$ solar cases, the mixing ratio of $\mathrm{CO}$ in the middle atmosphere can reach $\sim 10 \mathrm{ppm}$ and that of $\mathrm{CO}_{2} \sim 60 \mathrm{ppm}$. $\mathrm{HCN}$ would no longer be the most abundant nitrogen product, and its mixing ratio in the middle atmosphere can be reduced to $\sim 40$ ppm. In the $100 \times$ solar cases, both $\mathrm{CO}$ and $\mathrm{CO}_{2}$ can have very high mixing ratios $\left(>10^{-2}\right.$, and on the same order of $\left.\mathrm{CH}_{4}\right)$ in the middle atmosphere, and the above-cloud $\mathrm{H}_{2} \mathrm{O}$ would be consumed by photochemistry and have a mixing ratio of $\sim 10 \mathrm{ppm}$ at $10^{2} \mathrm{~Pa}$. The mixing ratio of $\mathrm{HCN}$ would be further reduced to $\sim 10 \mathrm{ppm}$, while still marginally greater than the mixing ratio at the quench point. 

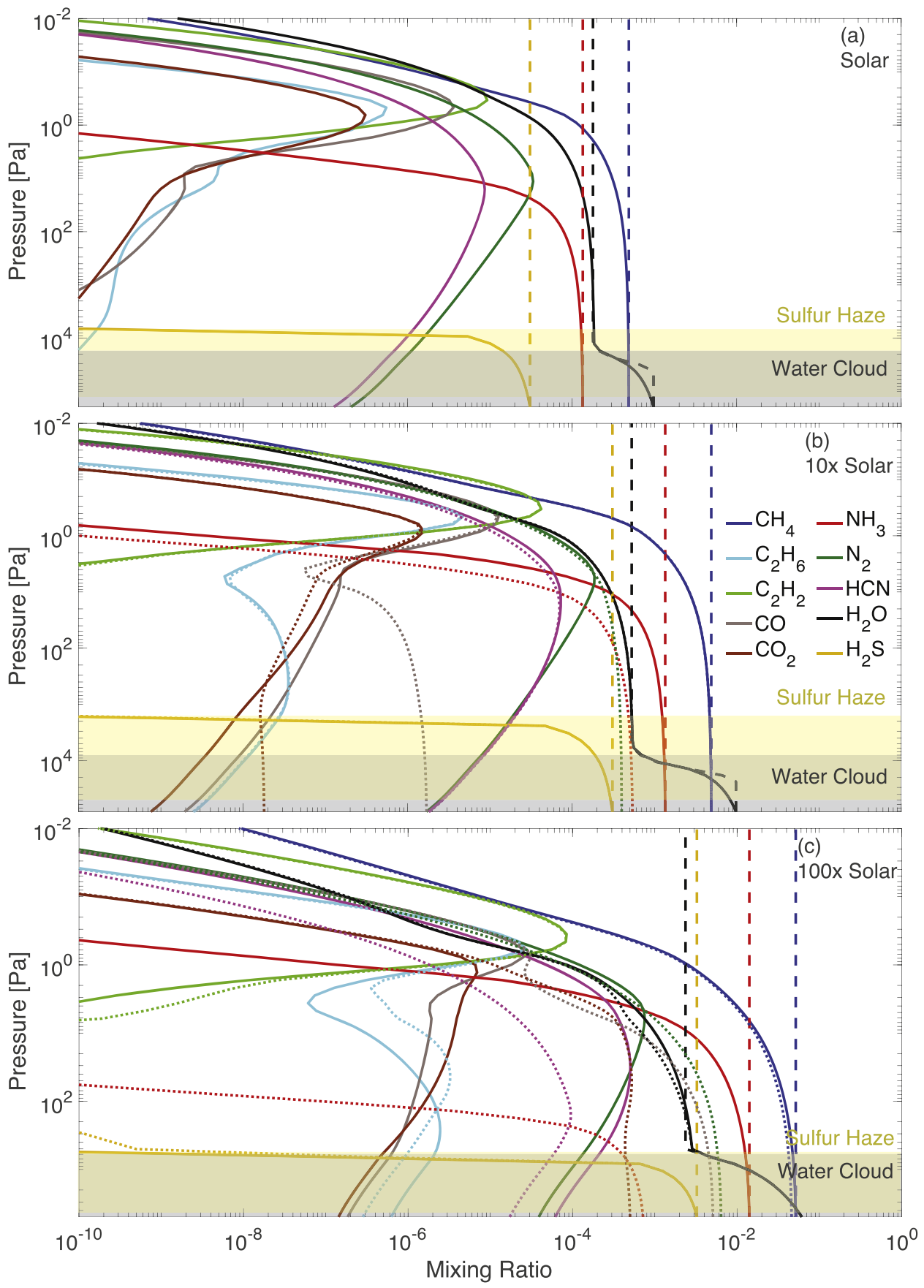

Figure 6. Modeled abundances of main gases and photochemical products in the temperate sub-Neptune K2-18 b for varied metallicities. Solid lines show the photochemical model results and the dashed lines show the equilibrium cloud condensation model results for comparison. Dotted lines in panels (b) and (c) show the photochemical model results that adopt the quench-point abundances of $\mathrm{CH}_{4}, \mathrm{CO}, \mathrm{CO}_{2}, \mathrm{NH}_{3}$, and $\mathrm{N}_{2}$ (Figure 3) at the lower boundary.

\subsubsection{Kepler-167 e: a Cold Planet around a G/K Star}

The atmosphere of Kepler- $167 \mathrm{e}$ is much colder than that of $\mathrm{K} 2-18 \mathrm{~b}$ or PH2 b, and its atmospheric chemistry is more akin to that of Jupiter (Atreya et al. 1977; Kaye \& Strobel 1983a, 1983b; Gladstone et al. 1996; Moses et al. 2005, 2010). Both $\mathrm{H}_{2} \mathrm{O}$ and $\mathrm{H}_{2} \mathrm{~S}$ are fully depleted by condensation or $\mathrm{NH}_{4} \mathrm{SH}$ formation, and the uppermost cloud predicted by the atmospheric structure model is $\mathrm{NH}_{3}$ ice. However, the steadystate results of the photochemical model indicate that photodissociation of $\mathrm{NH}_{3}$ should deplete the $\mathrm{NH}_{3}$ ice cloud. $\mathrm{NH}_{3}$ is photochemically depleted to the pressure of $7 \times$ $10^{4}-10^{3} \mathrm{~Pa}$ from the solar to $100 \times$ solar abundance cases. The main product of the photodissociation that can accumulate in the middle atmosphere is $\mathrm{N}_{2}$, while the mixing ratios of $\mathrm{HCN}$ and $\mathrm{N}_{2} \mathrm{H}_{4}$ are limited by condensation. The mixing ratio of $\mathrm{HCN}$ can reach $>1 \mathrm{ppm}$ below the condensation level in the $100 \times$ solar case.

The main photochemical gases of carbon are $\mathrm{C}_{2} \mathrm{H}_{6}$ and $\mathrm{C}_{2} \mathrm{H}_{2}$, with no $\mathrm{CO}$ or $\mathrm{CO}_{2}$ at appreciable mixing ratios. While the mixing ratio of $\mathrm{C}_{2} \mathrm{H}_{2}$ strongly peaks at $0.1 \mathrm{~Pa}$, where the photodissociation of $\mathrm{CH}_{4}$ takes place, the mixing ratio of $\mathrm{C}_{2} \mathrm{H}_{6}$ can be significant in the middle atmosphere. At $10^{2} \mathrm{~Pa}$, the mixing ratio of $\mathrm{C}_{2} \mathrm{H}_{6}$ is $\sim 2,4$, and $30 \mathrm{ppm}$ for the solar, $10 \times$ solar, and $100 \times$ solar abundance cases, respectively. If 

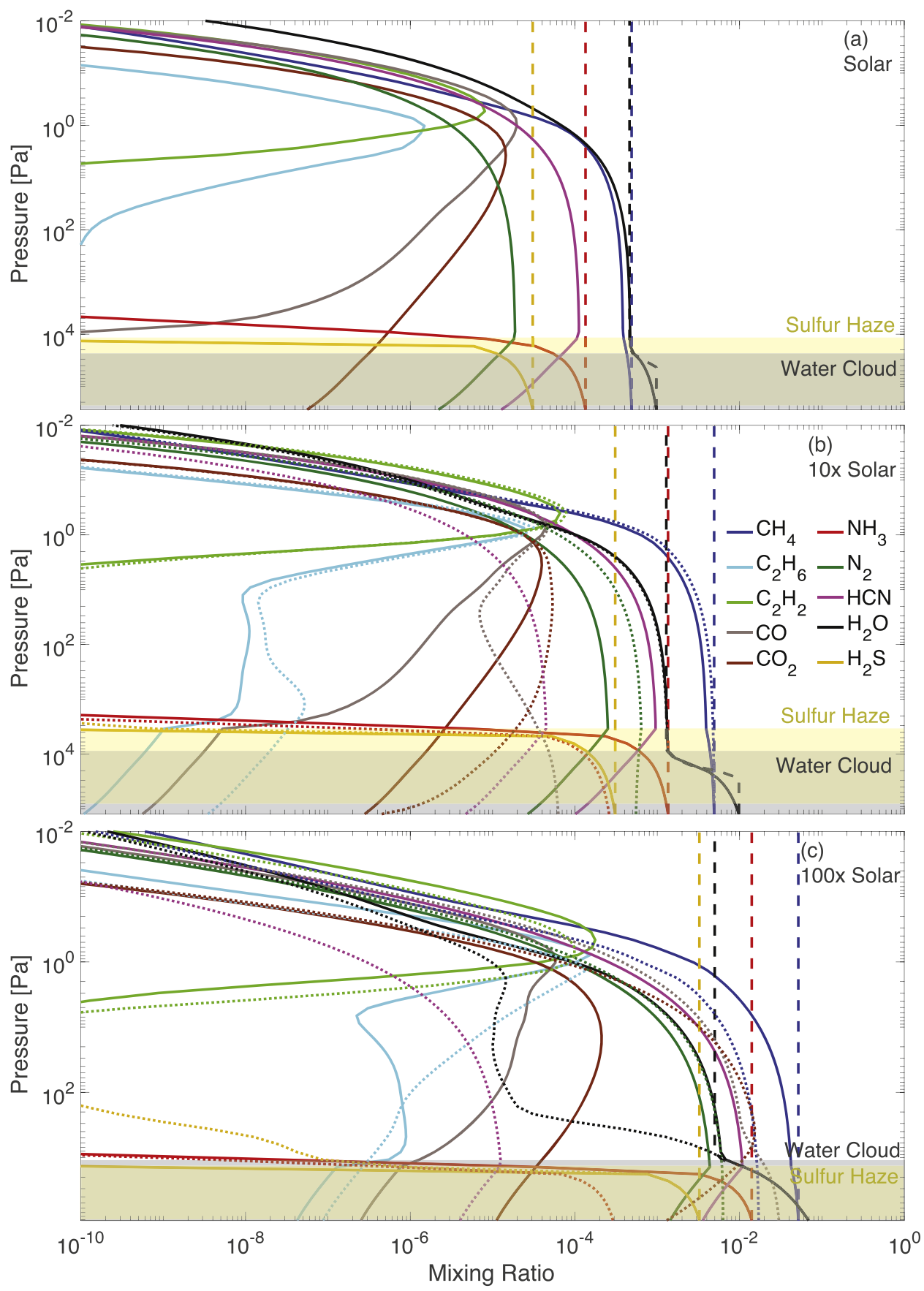

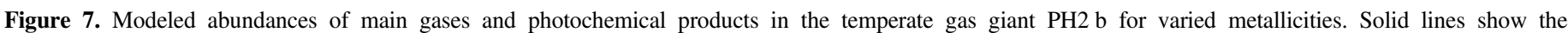

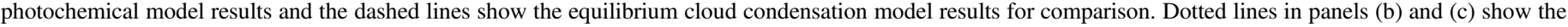
photochemical model results that adopt the quench-point abundances of $\mathrm{CH}_{4}, \mathrm{CO}, \mathrm{CO}_{2}, \mathrm{NH}_{3}$, and $\mathrm{N}_{2}($ Figure 4$)$ at the lower boundary.

the deep-tropospheric source of $\mathrm{CO}$ and $\mathrm{CO}_{2}$ is applied to the bottom of the photochemical domain, they can have substantial mixing ratios in the $100 \times$ solar case, while the mixing ratio of $\mathrm{C}_{2} \mathrm{H}_{6}$ is not strongly impacted.

\subsection{Photochemical Depletion of $\mathrm{NH}_{3}$}

From Figures 6-8, we see that $\mathrm{NH}_{3}$ is depleted to the cloud deck in temperate and cold planets around $\mathrm{G} / \mathrm{K}$ stars but remains intact in the middle atmosphere of temperate and cold planets around M stars. This finding is significant because it implies that $\mathrm{NH}_{3}$ should be detectable on temperate planets around $\mathrm{M}$ stars but not around $\mathrm{G} / \mathrm{K}$ stars (see Section 3.5).

The root cause of this different behavior is the $M$ stars (represented by GJ 176 here) emit substantially lower irradiation at the near-ultraviolet wavelengths than do the $\mathrm{G} / \mathrm{K}$ stars (represented by the Sun here; Figure 2). The radiation that dissociates $\mathrm{NH}_{3}$ in the $\mathrm{H}_{2}$-dominated atmosphere is the radiation that is not absorbed by the typically more abundant $\mathrm{CH}_{4}$ and $\mathrm{H}_{2} \mathrm{O} . \mathrm{NH}_{3}$ has a dissociation limit at $\sim 230 \mathrm{~nm}$, while for $\mathrm{CH}_{4}$ it is at $\sim 150 \mathrm{~nm}$ and for $\mathrm{H}_{2} \mathrm{O} \sim 240 \mathrm{~nm}$, but the cross section and the shielding effect of $\mathrm{H}_{2} \mathrm{O}$ is small, $>200 \mathrm{~nm}(\mathrm{Hu}$ et al. 2012; Ranjan et al. 2020). $\mathrm{C}_{2} \mathrm{H}_{2}$ also absorbs photons up 

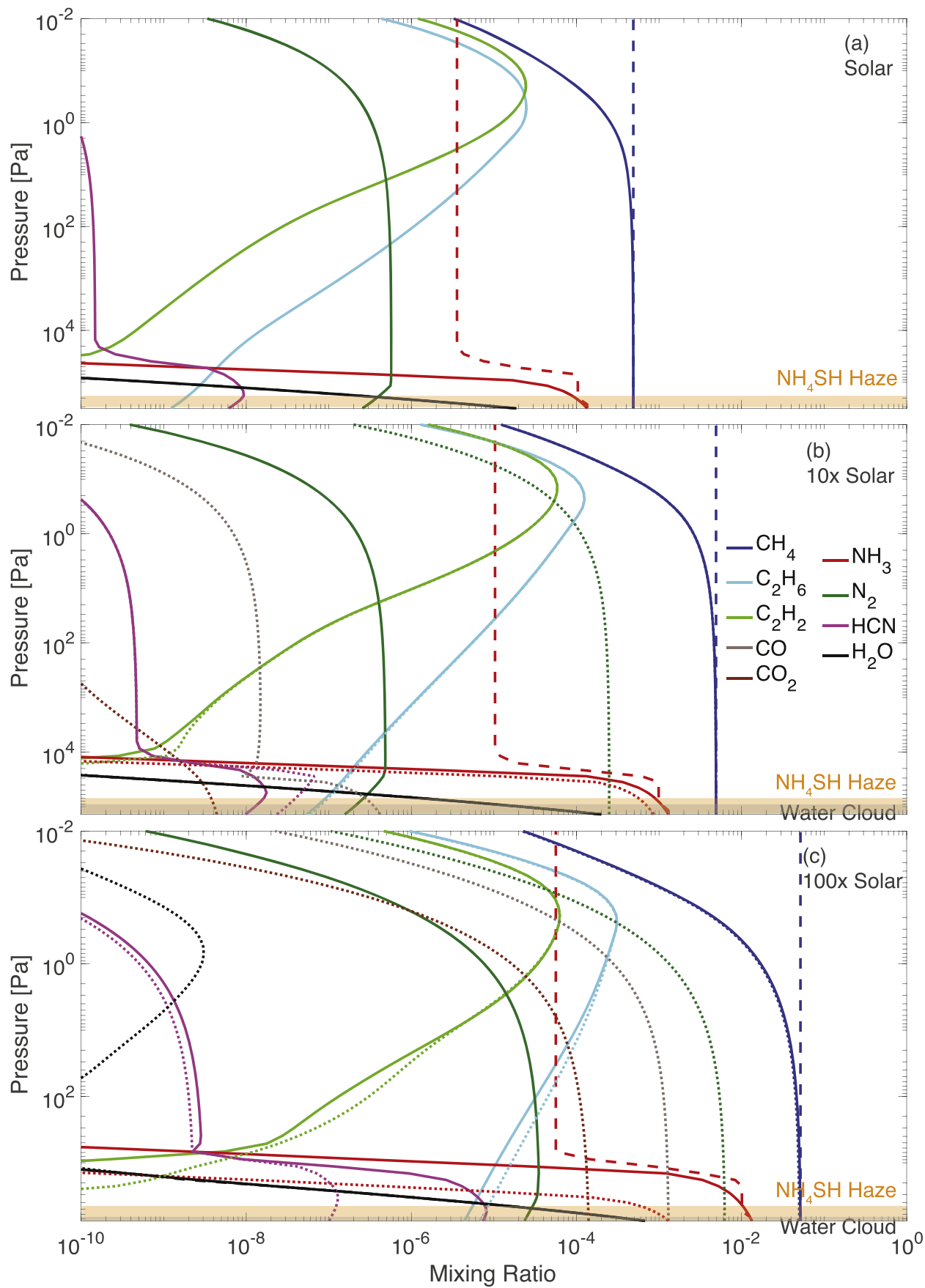

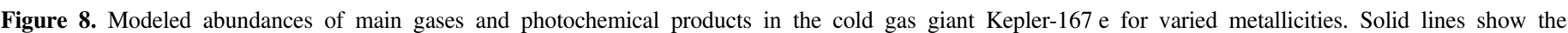

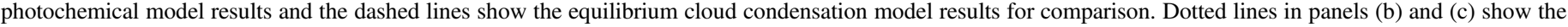
photochemical model results that adopt the quench-point abundances of $\mathrm{CH}_{4}, \mathrm{CO}, \mathrm{CO}_{2}, \mathrm{NH}_{3}$, and $\mathrm{N}_{2}($ Figure 5) at the lower boundary.

to $\sim 230 \mathrm{~nm}$ but it typically does not strongly interfere with the $\mathrm{NH}_{3}$ photodissociation due to its relatively low abundance. Thus, photons in the range $200-230 \mathrm{~nm}$ are the most relevant for the photodissociation of $\mathrm{NH}_{3}$ in $\mathrm{K} 2-18 \mathrm{~b}$ and $\mathrm{PH} 2 \mathrm{~b}$, and photons in the range $150-230 \mathrm{~nm}$ are the most relevant for Kepler-167 e. Having similar bolometric irradiation, the photon flux at $200-230 \mathrm{~nm}$ received by $\mathrm{PH} 2 \mathrm{~b}$ is more than that received by K2-18 b by $>2$ orders of magnitude (Figure 2 ). The photon flux received by Kepler-167 e is one order of magnitude more than for $\mathrm{K} 2-18 \mathrm{~b}$, and the removal of $\mathrm{NH}_{3}$ by condensation further pushes down the pressure of photochemical depletion (see below).

\subsubsection{Criterion of Photochemical Depletion}

How does the photon flux control the pressure of photochemical depletion? Guided by the numerical results, here we develop a simple theory that estimates the pressure of photochemical depletion. Assuming that photodissociation is the only process that removes $\mathrm{NH}_{3}$ with no recycling or production, its mixing ratio profile at the steady state should obey the following differential equation:

$$
\frac{d}{d z}\left(K N \frac{d f}{d z}\right)=f N J
$$


where $z$ is altitude, $K$ is the eddy diffusion coefficient, $N$ is the total number density of the atmosphere, $f$ is the mixing ratio, and $J$ is the photodissociation rate (often referred to as the " $J$ value" in the atmospheric chemistry literature). The number density has a scale height of $H$, and the equation can be rewritten as

$$
\frac{d^{2} f}{d z^{2}}-\frac{1}{H} \frac{d f}{d z}-\frac{J}{K} f=0 .
$$

Assuming $J, H$, and $K$ to be constant with respect to $z$, the equation above has the analytical solution of

$$
f=f_{0} \exp \left(\frac{z}{2}\left(\frac{1}{H}-\sqrt{\frac{1}{H^{2}}+\frac{4 J}{K}}\right)\right) \equiv f_{0} \exp \left(-\frac{\alpha z}{H}\right),
$$

where $f_{0}$ is the mixing ratio at the pressure of photochemical depletion ( $z=0$ for simplicity), and $\alpha$ is

$$
\alpha=\frac{1}{2}\left(\sqrt{1+\frac{4 J H^{2}}{K}}-1\right) .
$$

Therefore, when the product $4 J H^{2} / K$ is small, $\alpha \rightarrow 0$ and the mixing ratio profile is close to a constant; and when $4 \mathrm{JH}^{2} / \mathrm{K}$ is large, $\alpha$ can be $\gg 1$ and thus the mixing ratio drops off very quickly. This explains the vertical profiles of $\mathrm{NH}_{3}$ seen in Figures 6-8.

Going back to Equation (1), which can be integrated from the pressure of photochemical depletion to the top of the atmosphere, we have

$$
\left.K N \frac{d f}{d z}\right|_{z=\infty}-\left.K N \frac{d f}{d z}\right|_{z=0}=\int_{0}^{\infty} n(z) J(z) d z
$$

where $n \equiv f N$ is the number density of $\mathrm{NH}_{3}$. Assuming that the photoabsorption of $\mathrm{NH}_{3}$ itself is the sole source of opacity, $J$ can be expressed as

$$
J(z)=J_{\infty} \exp \left(-\sigma \int_{z}^{\infty} n\left(z^{\prime}\right) d z^{\prime}\right),
$$

where $J_{\infty}$ is the top-of-atmosphere $J$-value and $\sigma$ is the mean cross section of $\mathrm{NH}_{3}$. The differential of Equation (6) is

$$
\frac{d J}{d z}=\sigma n J
$$

Combining Equations (5) and (7), and recognizing $d f / d z$ vanishes at $z=\infty$, we obtain

$$
-\left.K N \frac{d f}{d z}\right|_{z=0}=\frac{1}{\sigma} \int_{0}^{\infty} \frac{d J}{d z} d z=\frac{J_{\infty}-J(z=0)}{\sigma} .
$$

With $J(z=0) \sim 0$ (i.e., the $J$-value immediately below the pressure of photochemical depletion is minimal), and $J_{\infty}=\sigma I$, where $I$ is the photon flux at the top of the atmosphere, we obtain

$$
-\left.K N \frac{d f}{d z}\right|_{z=0}=I .
$$

Note that to derive Equation (9), no specific profiles for $J$ or $n$ $(f)$ need to be assumed.

The physical meaning of Equation (9) is that the number of $\mathrm{NH}_{3}$ molecules that diffuse through the pressure of photochemical depletion should be equal to the number of photons

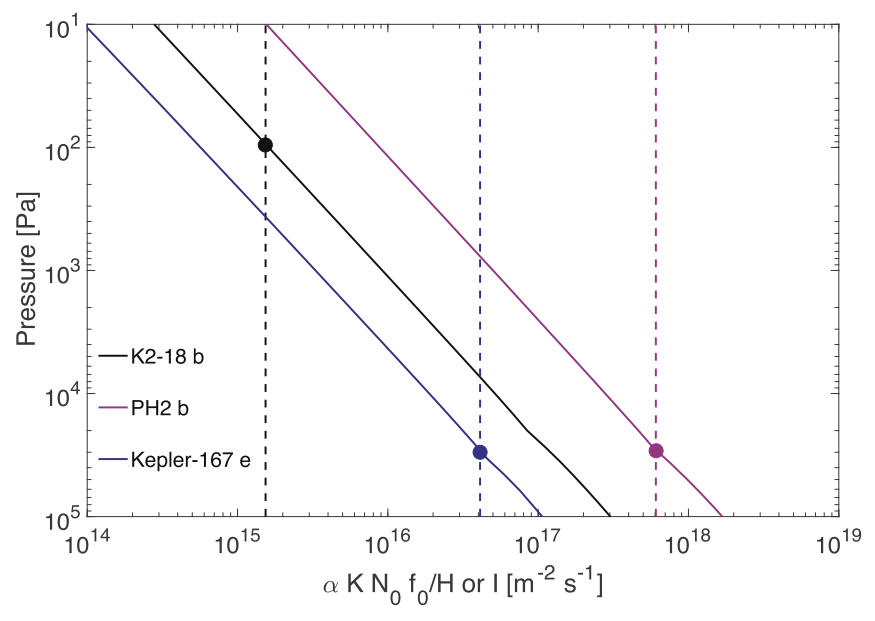

Figure 9. Pressure of photochemical depletion of $\mathrm{NH}_{3}$ predicted by the criterion in Equations (9) and (10). We compare the left-hand side (solid line) and right-hand side (dashed line) of Equation (10), assuming a solar abundance atmosphere. Where the solid line and the dashed line meet defines the pressure of photochemical depletion.

received at the top of the atmosphere. This physical condition would become evident if one regards the column of $\mathrm{NH}_{3}$ above the pressure of photochemical depletion as a whole and recognizes that one photon dissociates one molecule. To the extent that the photoabsorption of $\mathrm{NH}_{3}$ itself is the dominant source of opacity, the criterion expressed by Equation (9) does not depend on the mean cross section. Similarly, the criterion will be applicable to any molecule subject to photodissociation in a wavelength range largely free of interference by other molecules.

It should be noted that Equation (9) cannot be derived by requiring the pressure of photochemical depletion to occur roughly at the optical depth of unity for the photodissociating radiation. This is because the mixing ratio profile in Equation (3) is valid only locally and depends on $J$, which in turns depends on the vertical profile of the mixing ratio. As such, one cannot integrate Equation (3) directly to find the pressure of photochemical depletion, and the optical-depth-ofunity condition is not as predictive as Equation (9).

The left-hand side of Equation (9) can be evaluated locally using Equation (3), and Equation (9) becomes

$$
\frac{\alpha K N_{0} f_{0}}{H}=I,
$$

where $N_{0}$ and $f_{0}$ are the total number density and the mixing ratio at the pressure of photochemical depletion. The pressure is thus $P_{0}=N_{0} \mathrm{k}_{b} \mathrm{~T}$ where $k_{b}$ is the Boltzmann constant and $T$ is temperature. The term $\alpha$ can be evaluated with Equation (4) for a $J$ value that corresponds to $5 \%$ of the top-of-atmosphere value. Equation (10) thus provides a closed-form criterion that determines the pressure of photochemical depletion, and explains why the pressure of photochemical depletion is sensitive to the top-of-atmosphere flux of photons that drive photodissociation.

Figure 9 shows both sides of Equation (10) for the three planets modeled assuming a solar abundance atmosphere. We can see that the pressure of photochemical depletion implied by Equation (10) for $\mathrm{K} 2-18 \mathrm{~b}$ is $\sim 100 \mathrm{~Pa}$, consistent with the pressure where the photochemical model starts to substantially deviate from the equilibrium cloud condensation model 
(Figure 6). Figure 6 also shows that the mixing ratio $\mathrm{NH}_{3}$ decreases very slowly near the pressure of the photochemical depletion, but the decrease becomes faster for lower pressures, where the $J$ value and the $4 J H^{2} / K$ product become greater (see Equations (3) and (4)). The mixing ratio of $\mathrm{NH}_{3}$ eventually drops below $10^{-6}$ at the pressure lower than the pressure of photochemical depletion by approximately one order of magnitude. The pressures of photochemical depletion implied by Equation (10) for PH2 b and Kepler-167 e are close to or below the cloud deck (i.e., $10^{4}-10^{5} \mathrm{~Pa}$ ), which is consistent with numerical finding that $\mathrm{NH}_{3}$ is photodissociated to the cloud deck on these planets (Figures 7 and 8). Therefore, although Equation (10) cannot replace the full photochemical calculation due to the underlying assumptions (e.g., no recycling or production, self-shielding only), it provides a guiding estimate of whether a gas is likely depleted by photodissociation in the middle atmosphere.

\subsubsection{Sensitivity to the Eddy Diffusion Coefficient}

From the criterion of photochemical depletion (Equation (10)), we see that when the eddy diffusion coefficient increases, the pressure of photochemical depletion decreases. In other words, stronger mixing would sustain a photodissociated gas (e.g., $\mathrm{NH}_{3}$ ) to a lower pressure or higher altitude. We have used the photochemical model to conduct a sensitivity study of the eddy diffusion coefficient, and the results confirm this understanding (Figure 10). The most significant sensitivity happens with $\mathrm{PH} 2 \mathrm{~b}$ : the standard model predicts the photodissociation would deplete $\mathrm{NH}_{3}$ to the cloud deck, while with a 10-fold or 100-fold greater eddy diffusion coefficient, $\mathrm{NH}_{3}$ would be depleted at $10^{2} \sim 10^{3} \mathrm{~Pa}$. For Kepler-167e, with a 10 -fold or 100 -fold greater eddy diffusion coefficient, photodissociation can no longer deplete the $\mathrm{NH}_{3}$ ice cloud, while the mixing ratio of $\mathrm{NH}_{3}$ in the middle atmosphere remains small due to condensation and photodissociation above the cloud deck.

The top of the sulfur haze layer moves up in the atmosphere when the eddy diffusion coefficient increases. For both K2-18 b and $\mathrm{PH} 2 \mathrm{~b}$, the top of the sulfur haze would be at $\sim 10^{3} \mathrm{~Pa}$ and $10^{2} \mathrm{~Pa}$ for 10 -fold and 100-fold greater eddy diffusion coefficient (Figure 10). A haze layer that extends to $10^{2} \mathrm{~Pa}$ would greatly interfere with transmission spectroscopy and also affect the spectra of the reflected starlight (see Section 3.5). This trend is consistent with the findings of Zahnle et al. (2016) and is produced by two effects acting together. First, the pressure of photochemical depletion of $\mathrm{H}_{2} \mathrm{~S}$, the feedstock of sulfur haze, decreases for a greater eddy diffusion coefficient. Second, a stronger eddy diffusion helps increase the lifetime of haze particles against falling (see the formulation in $\mathrm{Hu}$ et al. 2012). For PH2 b, the extended sulfur haze layer further keeps $\mathrm{NH}_{3}$ from photochemical depletion by absorbing the ultraviolet photons that can dissociate $\mathrm{NH}_{3}$.

The sensitivity of main photochemical gases' abundance to the eddy diffusion coefficient is complex (Figure 10), which indicates several factors at work. For $\mathrm{N}_{2}$ and $\mathrm{HCN}$ (the dominant photochemical gases of nitrogen), their mixing ratios at the lower boundary decrease with the eddy diffusion coefficient. This is because, in our model, gases move across the lower boundary at a velocity that is proportional to the eddy diffusion coefficient, and the loss to the lower boundary is the main loss mechanism for both $\mathrm{N}_{2}$ and $\mathrm{HCN}$. Their mixing ratios in the middle atmosphere do not necessarily follow the same trend, as they also depend on the photochemical production (see Section 3.3). The abundance of the photochemical gases of carbon does not depend on the eddy diffusion coefficient monotonically, and this is because the formation rates of $\mathrm{CO}, \mathrm{CO}_{2}$, and $\mathrm{C}_{2} \mathrm{H}_{6}$ largely depend on the abundance of $\mathrm{H}, \mathrm{OH}$, and $\mathrm{O}$, which is in turn controlled by the full chemical network involving the photodissociation of $\mathrm{CH}_{4}$, $\mathrm{H}_{2} \mathrm{O}$, and $\mathrm{NH}_{3}$ (see Section 3.4). For example, in K2-18 b with the solar metallicity, both $\mathrm{CO}$ and $\mathrm{CO}_{2}$ have very small mixing ratios in the middle atmosphere in the standard case; the two would be substantially more abundant in the middle atmosphere with a 10-fold greater eddy diffusion coefficient, and CO would become more abundant than $\mathrm{CO}_{2}$ with a 100 -fold greater eddy diffusion coefficient. These examples highlight the richness and complexity of atmospheric photochemistry in temperate and cold planets.

\subsection{Photolysis of $\mathrm{NH}_{3}$ in the Presence of $\mathrm{CH}_{4}$}

A common phenomenon that emerges from the photochemical models is the synthesis of $\mathrm{HCN}$ in temperate and $\mathrm{H}_{2}$-rich exoplanets. The photodissociation of $\mathrm{NH}_{3}$ in Jupiter leads to $\mathrm{N}_{2}$ but not significant amounts of $\mathrm{HCN}$, and this is mainly because $\mathrm{NH}_{3}$ is dissociated at much higher pressures than $\mathrm{CH}_{4}$ (e.g., Atreya et al. 1977; Kaye \& Strobel 1983a, 1983b; Moses et al. 2010). HCN in Titan's $\mathrm{N}_{2}$-dominated atmosphere mainly comes from the reactions between atomic nitrogen and hydrocarbons and the associated chemical network (Yung et al. 1984; Lavvas et al. 2008; Krasnopolsky 2014; Vuitton et al. 2019). Similar processes, as well as the reactions between $\mathrm{CH}$ and $\mathrm{NO} / \mathrm{N}_{2} \mathrm{O}$ may also lead to formation of $\mathrm{HCN}$ on early Earth or rocky exoplanets with $\mathrm{N}_{2}$-dominated atmospheres irradiated by active stars (Airapetian et al. 2016; Rimmer \& Rugheimer 2019). In addition, the formation of $\mathrm{HCN}$ has been commonly found in warm and hot $\mathrm{H}_{2}$-rich exoplanets (e.g., Line et al. 2011; Moses et al. 2011; Venot et al. 2012; Agúndez et al. 2014; Mollière et al. 2015; Moses et al. 2016; Blumenthal et al. 2018; Kawashima \& Ikoma 2018; Hobbs et al. 2019; Lavvas et al. 2019; Molaverdikhani et al. 2019), and the mechanisms identified include quench kinetics (Moses et al. 2011; Venot et al. 2012; Agúndez et al. 2014) and photochemistry (Line et al. 2011; Kawashima \& Ikoma 2018; Hobbs et al. 2019). Here, we show that HCN can also build up to significant amounts in temperate exoplanets with $\mathrm{H}_{2}$-dominated atmospheres.

Figure 11 shows the chemical network that starts with the photodissociation of $\mathrm{NH}_{3}$ and ends with the formation of $\mathrm{N}_{2}$ and $\mathrm{HCN}$ as the main photochemical products. The key condition for the synthesis of $\mathrm{HCN}$ is the photodissociation of $\mathrm{NH}_{3}$ in the presence of $\mathrm{CH}_{4}$ and at a temperature $>\sim 200 \mathrm{~K}$. This condition allows $\mathrm{CH}_{3}$, one of the ingredients for the synthesis of $\mathrm{HCN}$, to be produced locally by the reaction between $\mathrm{CH}_{4}$ and $\mathrm{H}$, and this $\mathrm{H}$ is produced by the photodissociation of $\mathrm{NH}_{3}$ itself. We describe the details as follows.

The photodissociation of $\mathrm{NH}_{3}$ mainly produces $\mathrm{NH}_{2}$,

$$
\mathrm{NH}_{3} \stackrel{h \nu}{\rightarrow} \mathrm{NH}_{2}+\mathrm{H}
$$

and some of the $\mathrm{NH}_{2}$ produced is returned to $\mathrm{NH}_{3}$ via

$$
\mathrm{NH}_{2}+\mathrm{H}_{2} \rightarrow \mathrm{NH}_{3}+\mathrm{H}
$$





Figure 10. Sensitivity of the abundance profiles of $\mathrm{NH}_{3}$ and main photochemical gases to the eddy diffusion coefficient. The profiles of $\mathrm{H}_{2} \mathrm{O}$ and $\mathrm{CH}_{4}$ are not shown because their abundance in the middle atmosphere is not sensitive to the eddy diffusion coefficient. The horizontal orange lines show the top of the sulfur haze layer. The solid lines show the standard model, and the dashed and dashed-dotted lines show the models with 10-fold and 100-fold greater eddy diffusion coefficients, respectively. These models assume the solar abundance. A greater eddy diffusion coefficient causes the photodissociation of $\mathrm{NH}_{3}$ to occur at a lower pressure.

and

$$
\mathrm{NH}_{2}+\mathrm{H} \stackrel{M}{\rightarrow} \mathrm{NH}_{3}
$$

Another channel of the photodissociation of $\mathrm{NH}_{3}$ is to produce $\mathrm{NH}$

$$
\mathrm{NH}_{3} \stackrel{h \nu}{\rightarrow} \mathrm{NH}+\mathrm{H}_{2}
$$

The $\mathrm{NH}_{2}$ channel requires photons more energetic than $230 \mathrm{~nm}$ and the $\mathrm{NH}$ channel requires photons more energetic than
$165 \mathrm{~nm}$. Therefore, the photons that produce $\mathrm{NH}$ are more easily shielded by $\mathrm{H}_{2} \mathrm{O}$ and $\mathrm{CH}_{4}$. For the three planets modeled, the NH channel is important in K2-18 b and Kepler$167 \mathrm{e}$, but not in $\mathrm{PH} 2 \mathrm{~b}$. This is because the photodissociation of $\mathrm{NH}_{3}$ occurs at higher pressures in $\mathrm{PH} 2 \mathrm{~b}$ and is subject to the shielding effect of both $\mathrm{H}_{2} \mathrm{O}$ and $\mathrm{CH}_{4}$. The $\mathrm{NH}$ channel mostly leads to $\mathrm{N}_{2}$ (Figure 11).

The $\mathrm{NH}_{2}$ that is not recombined to form $\mathrm{NH}_{3}$ can undergo

$$
\mathrm{NH}_{2}+\mathrm{NH}_{2} \rightarrow \mathrm{N}_{2} \mathrm{H}_{4} \text {, }
$$




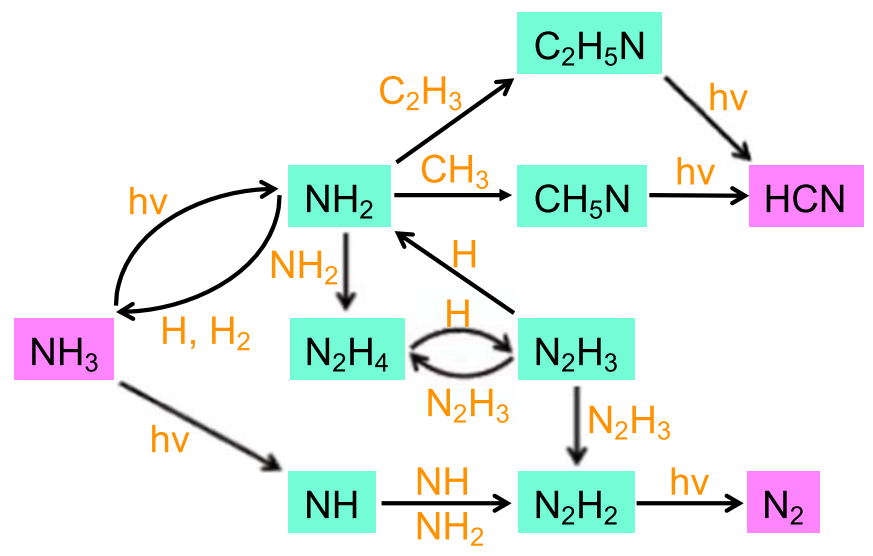

Figure 11. Chemical network from the photodissociation of $\mathrm{NH}_{3}$ in temperate and $\mathrm{H}_{2}$-dominated atmospheres. Not all reactions are shown, and the importance of the shown reactions changes from case to case. In the presence of $\mathrm{CH}_{4}, \mathrm{HCN}$ is one of the main photochemical products.

and the $\mathrm{N}_{2} \mathrm{H}_{4}$ produced (if not condensed out) can then become $\mathrm{N}_{2} \mathrm{H}_{3} . \quad \mathrm{N}_{2} \mathrm{H}_{3}$ can react with itself to form $\mathrm{N}_{2} \mathrm{H}_{2}$, whose photodissociation produces $\mathrm{N}_{2}$, or with $\mathrm{H}$ to return to $\mathrm{NH}_{2}$ (Figure 11). The other loss of $\mathrm{NH}_{2}$ is to react with $\mathrm{CH}_{3}$,

$$
\mathrm{NH}_{2}+\mathrm{CH}_{3} \rightarrow \mathrm{CH} 5 \mathrm{~N},
$$

followed by photodissociation to form $\mathrm{HCN}$,

$$
\mathrm{CH}_{5} \mathrm{~N} \stackrel{h \nu}{\rightarrow} \mathrm{HCN}+2 \mathrm{H}_{2} \text {. }
$$

Reaction (R6) is the critical step in this $\mathrm{HCN}$ formation mechanism, and it requires the $\mathrm{CH}_{3}$ radical to be available. The $\mathrm{CH}_{3}$ in Reaction (R6) is mainly produced by

$$
\mathrm{H}+\mathrm{CH}_{4} \rightarrow \mathrm{H}_{2}+\mathrm{CH}_{3} \text {. }
$$

Note that the photodissociation of $\mathrm{CH}_{4}$, which also produces $\mathrm{CH}_{3}$, does not contribute significantly to the source of $\mathrm{CH}_{3}$ in Reaction (R6) because the photodissociations of $\mathrm{CH}_{4}$ and $\mathrm{NH}_{3}$ typically occur at very different pressures. Another formational path of $\mathrm{HCN}$ is through

$$
\mathrm{NH}_{2}+\mathrm{C}_{2} \mathrm{H}_{3} \rightarrow \mathrm{C}_{2} \mathrm{H}_{5} \mathrm{~N}
$$

followed by photodissociation

$$
\mathrm{C}_{2} \mathrm{H}_{5} \mathrm{~N} \stackrel{h \nu}{\rightarrow} \mathrm{HCN}+\mathrm{CH}_{3}+\mathrm{H} \text {. }
$$

The $\mathrm{C}_{2} \mathrm{H}_{3}$ in Reaction (R9) is mainly produced by

$$
\mathrm{H}+\mathrm{C}_{2} \mathrm{H}_{2} \stackrel{M}{\rightarrow} \mathrm{C}_{2} \mathrm{H}_{3},
$$

and $\mathrm{C}_{2} \mathrm{H}_{2}$ is ultimately produced by the photodissociation of $\mathrm{CH}_{4}$ and then transported to the pressure of the photodissociation of $\mathrm{NH}_{3}$. The HCN produced in Reactions (R7) and (R10) is photodissociated to form $\mathrm{CN}$, but $\mathrm{CN}$ quickly reacts with $\mathrm{H}_{2}$ and $\mathrm{C}_{2} \mathrm{H}_{2}$ to return to $\mathrm{HCN}$. Thus, $\mathrm{HCN}$ does not have significant net chemical loss and is transported together with $\mathrm{N}_{2}$ through the lower boundary.

The $\mathrm{NH}_{3}-\mathrm{CH}_{4}$ coupling (Reactions (R6)-(R8)) dominates the formation of $\mathrm{HCN}$ over the $\mathrm{NH}_{3}-\mathrm{C}_{2} \mathrm{H}_{2}$ coupling (Reactions (R9)-(R11)) in temperate $\mathrm{H}_{2}$-dominated atmospheres by several orders of magnitude. This is because the mixing ratio of $\mathrm{C}_{2} \mathrm{H}_{2}$ at the pressure of $\mathrm{NH}_{3}$ photodissociation is typically very small on temperate planets like K2-18 b and $\mathrm{PH} 2 \mathrm{~b}$ (Figures 6 and 7). On colder planets like Kepler-167e, more $\mathrm{C}_{2} \mathrm{H}_{2}$ is available and the $\mathrm{NH}_{3}-\mathrm{C}_{2} \mathrm{H}_{2}$ coupling can contribute $1 \%-10 \%$ of the $\mathrm{HCN}$ formation, consistent with the results for Jupiter (Moses et al. 2010). We also note that past models of warm and hot $\mathrm{H}_{2}$-rich exoplanets suggested different reactions to represent the $\mathrm{NH}_{3}-\mathrm{CH}_{4}$ coupling, including $\mathrm{NH}+\mathrm{CH}_{3}$ (Line et al. 2011) and $\mathrm{N}+\mathrm{CH}_{3}$ (Kawashima \& Ikoma 2018; Hobbs et al. 2019); in our models the contribution from $\mathrm{N}+$ $\mathrm{CH}_{3} \rightarrow \mathrm{HCN}+\mathrm{H}_{2}$ contributes to the formation of $\mathrm{HCN}$ less than Reactions (R6)-(R8) by more than three orders of magnitude.

The efficacy of the $\mathrm{NH}_{2}$ path to produce $\mathrm{N}_{2}$ and $\mathrm{HCN}$ and the branching between $\mathrm{N}_{2}$ and $\mathrm{HCN}$ depend on the abundance of $\mathrm{H}$ and the temperature. Reaction (R8) has an activation energy of $33.60 \mathrm{~kJ} \mathrm{~mol}^{-1}$ (Baulch et al. 1992) and does not occur at very low temperatures. At the pressure of $\mathrm{NH}_{3}$ photodissociation, the temperature is $220-240 \mathrm{~K}$ in $\mathrm{K} 2-18 \mathrm{~b}$ and PH2 b, 120-130 K in Kepler-167 e, and $\sim 110 \mathrm{~K}$ in Jupiter. This makes Reaction (R8) faster by six orders of magnitude in K2-18 b and PH2 b than in Kepler-167 e or Jupiter, eventually leading to an efficient $\mathrm{HCN}$ production and a high abundance in the middle atmosphere. This is why the HCN production mechanism (Reactions (R6)-(R8)) does not operate efficiently in giant planets in the solar system but can build up $\mathrm{HCN}$ in warmer exoplanetary atmospheres.

The abundance of $\mathrm{H}$ is another important control. From Figure 11, we can see that a higher abundance of $\mathrm{H}$ would enhance the recycling from $\mathrm{N}_{2} \mathrm{H}_{4}$ to $\mathrm{NH}_{2}$, produce more $\mathrm{NH}_{3}$ to react with $\mathrm{NH}_{2}$, and help the return of $\mathrm{NH}_{2}$ to $\mathrm{NH}_{3}$. In other words, a higher abundance of $\mathrm{H}$ would reduce the overall efficacy of the $\mathrm{NH}_{2}$ path but favor the branch that leads to $\mathrm{HCN}$. At the pressure of $\mathrm{NH}_{3}$ photodissociation, the main source of $\mathrm{H}$ is the combination of Reactions (R1) and (R2), whose net result is the dissociation of $\mathrm{H}_{2}$ but not $\mathrm{NH}_{3}$. The sink of $\mathrm{H}$ is mainly Reaction (R3) and the direct recombination $\mathrm{H}+\mathrm{H} \stackrel{M}{\rightarrow} \mathrm{H}_{2}$. In high-metallicity atmospheres, another sink of $\mathrm{H}$ is Reaction (R5) followed by

$$
\mathrm{N}_{2} \mathrm{H}_{4}+\mathrm{H} \rightarrow \mathrm{N}_{2} \mathrm{H}_{3}+\mathrm{H}_{2},
$$

and

$$
\mathrm{N}_{2} \mathrm{H}_{3}+\mathrm{H} \rightarrow 2 \mathrm{NH}_{2} \text {. }
$$

The net result of Reactions (R5), (R12), and (R13) is $\mathrm{H}+\mathrm{H} \rightarrow \mathrm{H}_{2}$. Therefore, the chemical network that starts with the photodissociation of $\mathrm{NH}_{3}$ is both a source and a sink of $\mathrm{H}$, which feed back to determine the outcome of the network in a non-linear way. For example, the $\mathrm{NH}_{2}$ channel is a minor pathway to form $\mathrm{N}_{2}$ in the solar or $10 \times$ solar abundance atmosphere of $\mathrm{K} 2-18 \mathrm{~b}$, but it becomes an important pathway in the $100 \times$ solar atmosphere.

The abundance of $\mathrm{H}$ at the pressure of $\mathrm{NH}_{3}$ photodissociation also explains the different sensitivity of the HCN mixing ratio on the inclusion of a deep-tropospheric source of $\mathrm{CO} / \mathrm{CO}$ and a partial depletion of $\mathrm{NH}_{3}$. For K2-18 b, the reduction in the $\mathrm{HCN}$ mixing ratio is small or proportional to the reduction in the input $\mathrm{NH}_{3}$ abundance, but more reduction in the $\mathrm{HCN}$ mixing ratio is found for $\mathrm{PH} 2 \mathrm{~b}$ (Figures 6 and 7). This is because the photodissociation of $\mathrm{NH}_{3}$ occurs at higher pressures in $\mathrm{PH} 2 \mathrm{~b}$ than in $\mathrm{K} 2-18 \mathrm{~b}$. When abundant $\mathrm{CO}$ exists, the reactions $\mathrm{CO}+\mathrm{H} \stackrel{M}{\rightarrow} \mathrm{HCO}$ and $\mathrm{HCO}+\mathrm{H} \rightarrow \mathrm{CO}+\mathrm{H}_{2}$ efficiently remove $\mathrm{H}$. Note that the first reaction in this cycle is three-body and only significant at sufficiently high pressures. This sink of $\mathrm{H}$ results in the reduction of $\mathrm{CH}_{3}$ production 


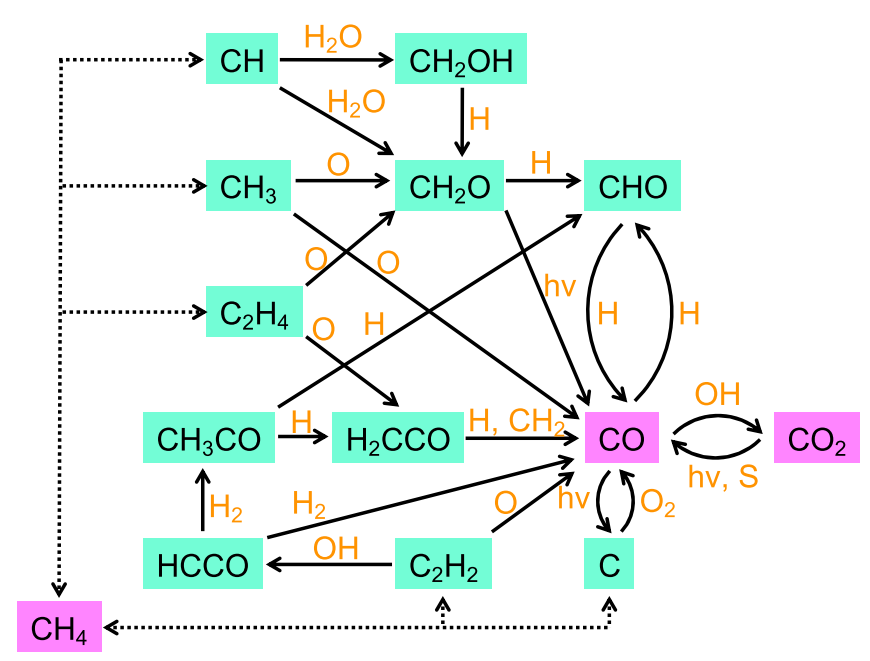

Figure 12. Chemical network from the photodissociations of $\mathrm{CH}_{4}$ and $\mathrm{H}_{2} \mathrm{O}$ in temperate/cold and $\mathrm{H}_{2}$-dominated atmospheres. Not all reactions are shown, and the importance of the shown reactions changes from case to case. The dashed links represent the chemical network of $\mathrm{CH}_{4}$ and hydrocarbons in cold and $\mathrm{H}_{2}$-dominated atmospheres, as standard in the literature (e.g., Gladstone et al. 1996; Moses et al. 2005). The photodissociation of $\mathrm{H}_{2} \mathrm{O}$ provides oxidizing radicals such as $\mathrm{OH}$. When $\mathrm{CH}_{4}$ is photodissociated together with $\mathrm{H}_{2} \mathrm{O}, \mathrm{CO}$ and $\mathrm{CO}_{2}$ can be formed in addition to hydrocarbons.

(Reaction R8) and thus disfavors the branch in the $\mathrm{NH}_{2}$ path that leads to $\mathrm{HCN}$.

To summarize, the numerical models and the $\mathrm{HCN}$ formation mechanism presented here indicate that $\mathrm{HCN}$ and $\mathrm{N}_{2}$ are generally the expected outcomes of the photodissociation of $\mathrm{NH}_{3}$ in gaseous exoplanets that receive stellar irradiance approximately equal to Earth's, regardless of the stellar type.

\subsection{Photolysis of $\mathrm{CH}_{4}$ Together with $\mathrm{H}_{2} \mathrm{O}$}

The formation of $\mathrm{CO}$ and $\mathrm{CO}_{2}$ as the most abundant photochemical gases of carbon on $\mathrm{K} 2-18 \mathrm{~b}$ and $\mathrm{PH} 2 \mathrm{~b}$ is another significant finding of our numerical models. The photodissociation of $\mathrm{CH}_{4}$ in colder $\mathrm{H}_{2}$-dominated atmospheres - such as the giant planets' atmospheres in the solar systemproduces hydrocarbons such as $\mathrm{C}_{2} \mathrm{H}_{6}$ and $\mathrm{C}_{2} \mathrm{H}_{2}$ but not oxygenated species (e.g., Gladstone et al. 1996; Moses et al. 2005). This is because $\mathrm{H}_{2} \mathrm{O}$ condenses out and is almost completely removed from the above-cloud atmosphere (such as in Kepler-167 e, Figure 8). External sources such as comets and interplanetary dust can supply oxygen to the upper atmospheres of Jupiter and the other giant planets (e.g., Moses et al. 2005; Dobrijevic et al. 2020), but we do not include this source in the present study. For warmer planets, however, $\mathrm{H}_{2} \mathrm{O}$ is only moderately depleted by condensation. The above-cloud water is photodissociated at approximately the same pressure as is $\mathrm{CH}_{4}$ (Figures 6 and 7). The photodissociations of $\mathrm{CH}_{4}$ and $\mathrm{H}_{2} \mathrm{O}$ together in $\mathrm{H}_{2}$-dominated atmospheres produce a chemical network beyond hydrocarbons (Figure 12) and eventually lead to the formation of $\mathrm{CO}$ and $\mathrm{CO}_{2}$. Even warmer atmospheres (e.g., the atmosphere of GJ $1214 \mathrm{~b}$ with an effective temperature of $500-600 \mathrm{~K})$ may also have $\mathrm{CO}$ and $\mathrm{CO}_{2}$ as the most abundant photochemical gases of carbon (e.g., Kempton et al. 2011; Kawashima \& Ikoma 2018).

The photodissociation of $\mathrm{CH}_{4}$ and the subsequent chemical reactions produce a wealth of hydrocarbons and radicals, and many of them (e.g., C, $\mathrm{CH}, \mathrm{CH}_{3}, \mathrm{C}_{2} \mathrm{H}_{2}$, and $\mathrm{C}_{2} \mathrm{H}_{4}$ ) lead to chemical pathways that form CO (Figure 12). Between K2-18 b and $\mathrm{PH} 2 \mathrm{~b}$ and among the modeled metallicities, we do not see a monotonic trend regarding the relative contribution of these $\mathrm{CO}$ forming pathways, probably due to many chemical cycles and feedback in hydrocarbon photochemistry. $\mathrm{CO}$ is converted to $\mathrm{CO}_{2}$ by the reaction with $\mathrm{OH}$ :

$$
\mathrm{CO}+\mathrm{OH} \rightarrow \mathrm{CO}_{2}+\mathrm{H} .
$$

Reaction (R14) is the dominant source of $\mathrm{CO}_{2}$ in all models, and the only significant chemical loss of $\mathrm{CO}_{2}$ is to form $\mathrm{CO}$ via either photodissociation or the reaction with elemental sulfur when available (Figure 12). The $\mathrm{CO}_{2}$ that is not returned to $\mathrm{CO}$ is then transported through the lower boundary.

What are the sources of $\mathrm{OH}, \mathrm{O}$, and $\mathrm{H}$ that power the chemical pathways shown in Figure 12? At the pressure of $\mathrm{CH}_{4}$ and $\mathrm{H}_{2} \mathrm{O}$ photodissociation, the source of $\mathrm{OH}$ is the photodissociation of water,

$$
\mathrm{H}_{2} \mathrm{O} \stackrel{h \nu}{\rightarrow} \mathrm{H}+\mathrm{OH}
$$

and the main sink is the reaction with $\mathrm{H}_{2}$,

$$
\mathrm{OH}+\mathrm{H}_{2} \rightarrow \mathrm{H}_{2} \mathrm{O}+\mathrm{H} \text {. }
$$

Reaction (R16) is the main sink of $\mathrm{OH}$ in all models, which means that the use of $\mathrm{OH}$ in the chemical pathways shown in Figure 12 does not usually become the dominant sink of $\mathrm{OH}$. Reactions (R15) and (R16) together are equivalent to the net dissociation of $\mathrm{H}_{2}$, which overtakes the photodissociation of $\mathrm{CH}_{4}$ and subsequent hydrocarbon reactions as the dominant source of $\mathrm{H}$ in temperate atmospheres. Lastly, the main source of $\mathrm{O}$ is the photodissociation of $\mathrm{CO}$ and $\mathrm{CO}_{2}$, which eventually traces to $\mathrm{OH}$ and the photodissociation of water.

At this point we can explain the ratio between $\mathrm{CO}_{2}$ and $\mathrm{CO}$ in the middle atmosphere, which is $\sim 1$ on $\mathrm{K} 2-18 \mathrm{~b}$ and $\sim 10$ on $\mathrm{PH} 2 \mathrm{~b}$ (Figures 6 and 7). Because Reaction (R14) is the main source of $\mathrm{CO}_{2}$ and photodissociation is the main sink, the number density of $\mathrm{CO}_{2}$ is $\sim k_{R 14}[\mathrm{CO}][\mathrm{OH}] / J_{\mathrm{CO}_{2}}$, where $k$ is the reaction rate constant and [] means the number density of a molecule. Because Reaction (R15) is the main source of $\mathrm{OH}$, the number density of $\mathrm{OH}$ is $\propto \mathrm{J}_{\mathrm{H}_{2} \mathrm{O}}\left[\mathrm{H}_{2} \mathrm{O}\right]$. Therefore, the ratio between $\mathrm{CO}_{2}$ and $\mathrm{CO}$ is $\propto J_{\mathrm{H}_{2} \mathrm{O}}\left[\mathrm{H}_{2} \mathrm{O}\right] / J_{\mathrm{CO}_{2}}$. For any given metallicity, the abundance of $\mathrm{H}_{2} \mathrm{O}$ in the middle atmosphere of $\mathrm{PH} 2 \mathrm{~b}$ is $3 \sim 5$-fold greater than that in $\mathrm{K} 2-18 \mathrm{~b}$ because $\mathrm{PH} 2 \mathrm{~b}$ is slightly warmer (Figures 6 and 7). And, $J_{\mathrm{H}_{2} \mathrm{O}}$ at the top of the atmosphere on $\mathrm{PH} 2 \mathrm{~b}$ is approximately twice that on $\mathrm{K} 2-18 \mathrm{~b}$, while $J_{\mathrm{CO}_{2}}$ is similar between the two planets (Figure 2). Together, this causes the $\left[\mathrm{CO}_{2}\right] /[\mathrm{CO}]$ ratio to be greater in the atmosphere of $\mathrm{PH} 2 \mathrm{~b}$ than in $\mathrm{K} 2-18 \mathrm{~b}$ by $\sim 10$-fold.

This trend to maintain the $\left[\mathrm{CO}_{2}\right] /[\mathrm{CO}]$ ratio also controls how the atmosphere reacts to a deep-tropospheric source of $\mathrm{CO}$ and $\mathrm{CO}_{2}$ that is applied as input at the lower boundary. The input $\mathrm{CO}_{2}$ is always less than $\mathrm{CO}$ by one or more orders of magnitude (Figures 3-5). On $\mathrm{PH} 2 \mathrm{~b}$, photochemical processes convert $\mathrm{CO}$ into $\mathrm{CO}_{2}$ in the middle atmosphere $\left(\sim 10^{2} \mathrm{~Pa}\right)$, and cause the steady-state mixing ratio of $\mathrm{CO}_{2}$ to be greater than that of CO. This conversion even becomes a significant sink of $\mathrm{H}_{2} \mathrm{O}$ and causes $\mathrm{H}_{2} \mathrm{O}$ to be depleted in the middle atmosphere in the $100 \times$ solar metallicity case (Figure 7). The $\mathrm{CO}$ to $\mathrm{CO}_{2}$ conversion is not so strong in the atmosphere of $\mathrm{K} 2-18 \mathrm{~b}$ or Kepler-167 e, and their mixing ratios in the middle atmosphere are largely the input values at the lower boundary (Figure 6). 
Finally, let us turn to the impact of $\mathrm{H}_{2} \mathrm{O}$ and $\mathrm{NH}_{3}$ photodissociation on the hydrocarbon chemistry. Compared with Kepler-167 e, the mixing ratio of $\mathrm{C}_{2} \mathrm{H}_{6}$ - the dominant, supposedly long-lived hydrocarbon-in $\mathrm{K} 2-18 \mathrm{~b}$ and $\mathrm{PH} 2 \mathrm{~b}$ is smaller and sometimes features an additional peak near the cloud deck (Figures 6-8). Particularly, the atmospheres of K2$18 \mathrm{~b}$ and $\mathrm{PH} 2 \mathrm{~b}$ have a strong sink of $\mathrm{C}_{2} \mathrm{H}_{6}$ at $\sim 1-10 \mathrm{~Pa}$, while the atmosphere of Kepler-167e does not. This sink is ultimately because of the high abundance of $\mathrm{H}$ produced by the photodissociation of $\mathrm{H}_{2} \mathrm{O}$ (Reactions (R15) and (R16)). The detailed reaction path involves the formation of $\mathrm{C}_{2} \mathrm{H}_{5}$ from $\mathrm{C}_{2} \mathrm{H}_{6}$ (by direct reaction with $\mathrm{H}$ or photodissociation to form $\mathrm{C}_{2} \mathrm{H}_{4}$ followed by $\mathrm{H}$ addition), and then $\mathrm{C}_{2} \mathrm{H}_{5}+\mathrm{H} \rightarrow 2 \mathrm{CH}_{3}$. Because of the abundance of $\mathrm{H}, \mathrm{CH}_{3}$ mostly combines with $\mathrm{H}$ to form $\mathrm{CH}_{4}$, rather than recombines to form $\mathrm{C}_{2} \mathrm{H}_{6}$. It is well known that the abundance of hydrocarbons is fundamentally controlled by the relative strength between $\mathrm{H}+\mathrm{CH}_{3} \stackrel{M}{\rightarrow} \mathrm{CH}_{4}$ and $\mathrm{CH}_{3}+\mathrm{CH}_{3} \stackrel{M}{\rightarrow} \mathrm{C}_{2} \mathrm{H}_{6}$ (e.g., Gladstone et al. 1996; Moses et al. 2005). Here, we find that the added $\mathrm{H}$ from $\mathrm{H}_{2} \mathrm{O}$ photodissociation results in a net sink for $\mathrm{C}_{2} \mathrm{H}_{6}$ in $\mathrm{K} 2-18 \mathrm{~b}$ and $\mathrm{PH}-2 \mathrm{~b}$ at $\sim 1-10 \mathrm{~Pa}$ and limits the abundance of hydrocarbons in their atmospheres. This sink does not exist in the atmosphere of Kepler-167 e, because little $\mathrm{H}_{2} \mathrm{O}$ photodissociation occurs in its atmosphere. Additionally, near the cloud deck, the temperature is warmer, and Reaction (R8) that uses $\mathrm{H}$ from the photodissociation of $\mathrm{NH}_{3}$ provides an additional source of $\mathrm{CH}_{3}$, and some of the $\mathrm{CH}_{3}$ becomes $\mathrm{C}_{2} \mathrm{H}_{6}$ and thus it peaks near the cloud deck. The formation of hydrocarbons is thus strongly impacted by the water and nitrogen photochemistry.

\subsection{Spectral Features of $\mathrm{H}_{2} \mathrm{O}, \mathrm{CH}_{4}, \mathrm{NH}_{3}$, and Photochemical Gases}

\subsubsection{Transmission Spectra}

Figures 13-15 show the transmission spectra of the temperate and cold planets K2-18 b, PH2 b, and Kepler$167 \mathrm{e}$, based on the gas and sulfur haze profiles simulated by the photochemical models. These modeled spectra can be regarded as the canonical examples of a temperate (Earth-like insolation) planet irradiated by an M dwarf star (K2-18 b, and also TOI-1231b), a temperate (Earth-like insolation) planet irradiated by a $\mathrm{G} / \mathrm{K}$ star $(\mathrm{PH} 2 \mathrm{~b})$, and a cold $(\sim 0.1 \times$ Earth insolation) planet irradiated by a G/K star (Kepler-167 e). Here, we focus on the wavelength range $0.5-5.0 \mu \mathrm{m}$, where several instruments on JWST will provide spectral capabilities (e.g., Beichman et al. 2014).

For K2-18 b, the equilibrium gases $\mathrm{CH}_{4}, \mathrm{H}_{2} \mathrm{O}$, and $\mathrm{NH}_{3}$, as well as the photochemical gas $\mathrm{HCN}$ have potentially detectable spectral features in the visible to mid-infrared wavelengths (Figure 13). Adding deep-tropospheric source of $\mathrm{CO}, \mathrm{CO}_{2}$, and $\mathrm{N}_{2}$ and sink of $\mathrm{NH}_{3}$ does not cause a significant change of the spectrum of a $10 \times$ solar metallicity atmosphere. However, a $100 \times$ solar metallicity atmosphere with deep-tropospheric source and sink would be free of the spectral features of $\mathrm{NH}_{3}$ or $\mathrm{HCN}$, but instead have potentially detectable features of $\mathrm{CO}_{2}$ and $\mathrm{CO}$.

Strikingly, the models from $1 \times$ to $100 \times$ solar abundance and with the standard eddy diffusion coefficient provide good fits to the existing transit depth measurements by K2, HST, and Spitzer (Benneke et al. 2019; Tsiaras et al. 2019). The models with a 100-fold greater eddy diffusion coefficient would have the sulfur haze layer extending to $10^{2} \mathrm{~Pa}$ and mute the spectral features in 1.1-1.7 $\mu \mathrm{m}$, at odds with the HST data. Both $\mathrm{CH}_{4}$ and $\mathrm{H}_{2} \mathrm{O}$ contribute to the spectral modulations seen by HST, which may have caused the difficulties in the identification of the gases by spectral retrieval (Benneke et al. 2019; Tsiaras et al. 2019; Blain et al. 2021).

$\mathrm{HCN}$, one of the most abundant photochemical gases in the middle atmosphere, is likely detectable in $\mathrm{K} 2-18 \mathrm{~b}$ via its spectral band at $\sim 3.0 \mu \mathrm{m}$. The $\mathrm{HCN}$ is produced from the photodissociation of $\mathrm{NH}_{3}$ in the presence of $\mathrm{CH}_{4}$. Also at $3.0 \mu \mathrm{m}$ are the absorption bands of $\mathrm{NH}_{3}$ and to a lesser extent $\mathrm{C}_{2} \mathrm{H}_{2}$. It would be possible to disentangle these bands with a reasonably wide wavelength coverage because $\mathrm{NH}_{3}$ has multiple and more prominent bands in the mid-infrared (Figure 13), and because $\mathrm{C}_{2} \mathrm{H}_{2}$ should have a minimal abundance in the middle atmosphere (Figure 6) and contribute little to the transmission spectra.

The spectral bands of $\mathrm{CO}_{2}$ and $\mathrm{CO}$ can be seen in the modeled spectra (in $4-5 \mu \mathrm{m}$ ) of $\mathrm{K} 2-18 \mathrm{~b}$ only when the atmosphere has supersolar metallicity and the transport from the deep troposphere is taken into account (Figure 13). In other words, the $\mathrm{CO}$ and $\mathrm{CO}_{2}$ that are produced from the photodissociation of $\mathrm{CH}_{4}$ together with $\mathrm{H}_{2} \mathrm{O}$ would have too low mixing ratios to be detected. The photodissociation of $\mathrm{CH}_{4}$ also produces $\mathrm{C}_{2} \mathrm{H}_{6}$. While $\mathrm{C}_{2} \mathrm{H}_{6}$ has strong bands at 3.35 and $12 \mu \mathrm{m}$, they would not be detectable due to its relatively low abundance and the strong $\mathrm{CH}_{4}$ and $\mathrm{NH}_{3}$ bands at the same wavelength, respectively (Figure 13).

For $\mathrm{PH} 2 \mathrm{~b}$, prominent spectral bands of $\mathrm{CH}_{4}, \mathrm{H}_{2} \mathrm{O}$, and the photochemical gases $\mathrm{CO}_{2}$ and $\mathrm{HCN}$ can be expected (Figure 14). $\mathrm{NH}_{3}$ is not detectable because it is depleted by photodissociation to the cloud deck (Figure 7). Even though its pressure of photochemical depletion can be reduced to $\sim 10^{2} \mathrm{~Pa}$ for a large eddy diffusion coefficient, the sulfur haze in that case would mute spectral features that are generated from approximately the same pressure levels (Figure 10) and thus cause $\mathrm{NH}_{3}$ to be undetectable. $\mathrm{HCN}, \mathrm{CO}_{2}$, and $\mathrm{CO}$ are the most abundant photochemical gases (Figure 7); but the $\mathrm{CO}$ bands are intrinsically weaker and so $\mathrm{CO}_{2}$ and $\mathrm{HCN}$ are the detectable photochemical gases via their spectral bands at 4.2 and $3.0 \mu \mathrm{m}$, respectively. Similar to $\mathrm{K} 2-18 \mathrm{~b}$, adding a deep-tropospheric source of $\mathrm{CO}, \mathrm{CO}_{2}$, and $\mathrm{N}_{2}$ and sink of $\mathrm{NH}_{3}$ does not cause a significant change of the spectrum of a $10 \times$ solar metallicity atmosphere. However, a $100 \times$ solar metallicity atmosphere with a deep-tropospheric source and sink would not have the spectral features of $\mathrm{H}_{2} \mathrm{O}$ or $\mathrm{HCN}$ and would have more prominent features of $\mathrm{CO}_{2}$ and $\mathrm{CO}$, as predicted by the photochemical model (Figure 7).

Lastly for the cold planet Kepler-167e, the transmission spectra will be dominated by the absorption bands of $\mathrm{CH}_{4}$ (Figure 15), as $\mathrm{H}_{2} \mathrm{O}$ is completely removed by condensation and $\mathrm{NH}_{3}$ by condensation and photodissociation. For a large eddy diffusion coefficient, the pressure of photochemical depletion of $\mathrm{NH}_{3}$ can be reduced to $\sim 10^{3} \mathrm{~Pa}$ (Figure 10) and this can produce a spectral band of $\mathrm{NH}_{3}$ at $\sim 3.0 \mu \mathrm{m}$. Thus, a search for this absorption band in the transmission spectra may constrain the eddy diffusion coefficient, although to distinguish it with a small peak due to the combined absorption of the photochemical gases $\mathrm{HCN}$ and $\mathrm{C}_{2} \mathrm{H}_{2}$ (Figure 15) may involve quantification through photochemical models. The main photochemical gas in this cold atmosphere $\mathrm{C}_{2} \mathrm{H}_{6}$ has spectral bands at 3.35 and $12 \mu \mathrm{m}$. The $3.35 \mu \mathrm{m}$ band is buried by a strong $\mathrm{CH}_{4}$ band, and while not shown in Figure 15, the $12 \mu \mathrm{m}$ 

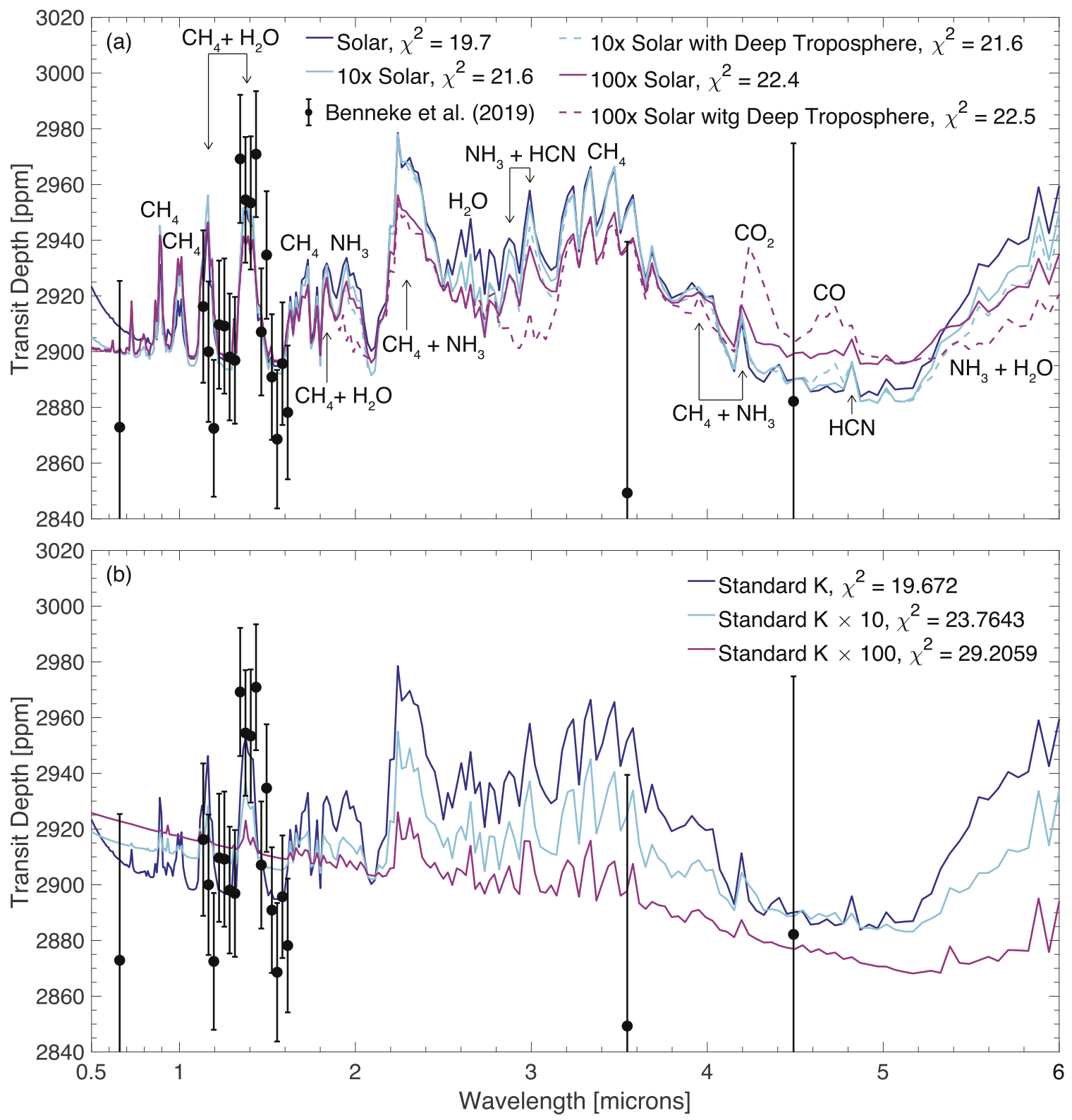

Figure 13. Modeled transmission spectra of the temperate sub-Neptune K2-18 b for varied metallicities (a) and varied eddy diffusion coefficients at solar metallicity (b). The dashed lines show model spectra with a deep-tropospheric source of $\mathrm{CO}, \mathrm{CO}_{2}$, and $\mathrm{N}_{2}$ and sink of $\mathrm{NH}_{3}$. All models with the standard eddy diffusion coefficient fit the observed transit depths. The equilibrium gases $\left(\mathrm{CH}_{4}, \mathrm{H}_{2} \mathrm{O}\right.$, and $\left.\mathrm{NH}_{3}\right)$ and the photochemical gas $\mathrm{HCN}$ are detectable in the wavelength range 0.5-5.0 $\mu \mathrm{m}$. The $100 \times$ solar metallicity atmosphere with a deep-tropospheric source and sink can have detectable features of $\mathrm{CO}_{2}$ and $\mathrm{CO}$.

band might be detectable given appropriate instrumentation with the spectral capability in the corresponding wavelength range. Finally, the deep-troposphere-sourced $\mathrm{CO}_{2}$ and $\mathrm{CO}$ in a $100 \times$ solar metallicity atmosphere may produce detectable spectral features at $4-5 \mu \mathrm{m}$.

To summarize, transmission spectroscopy from the visible to mid-infrared wavelengths can provide the sensitivity to detect the equilibrium gases $\mathrm{CH}_{4}$ and $\mathrm{H}_{2} \mathrm{O}$, and the photochemical gases $\mathrm{HCN}$, and in some cases $\mathrm{CO}_{2}$ in temperate/cold and $\mathrm{H}_{2}$-rich exoplanets. We do not expect $\mathrm{C}_{2} \mathrm{H}_{6}$ to be detectable. $\mathrm{NH}_{3}$ would be detectable on temperate planets around $\mathrm{M}$ dwarf stars but not detectable on temperate planets around $\mathrm{G} / \mathrm{K}$ stars. The deep-tropospheric source and sink can have a major impact only on the transmission spectrum of a $100 \times$ solar metallicity atmosphere, where typically the features of $\mathrm{NH}_{3}$ and $\mathrm{HCN}$ would be reduced and those of $\mathrm{CO}_{2}$ and $\mathrm{CO}$ would be amplified. The detection and nondetection of these gases will thus test the photochemical model and improve our understanding of the photochemical mechanisms as well as tropospheric transport in temperate/cold and $\mathrm{H}_{2}$-dominated atmospheres.

\subsubsection{Spectra of the Reflected Starlight}

The temperate and cold planets around $\mathrm{G} / \mathrm{K}$ stars are widely separated from their host stars and may thus also be characterized in the reflected starlight by direct imaging. Figure 16 shows the geometric albedo spectra of $\mathrm{PH} 2 \mathrm{~b}$ and Kepler-167e in the visible and near-infrared wavelengths that approximately correspond to the Roman Space Telescope's coronagraph instrument (Kasdin et al. 2020) and its potential Starshade Rendezvous (Seager et al. 2019) and the HabEx 

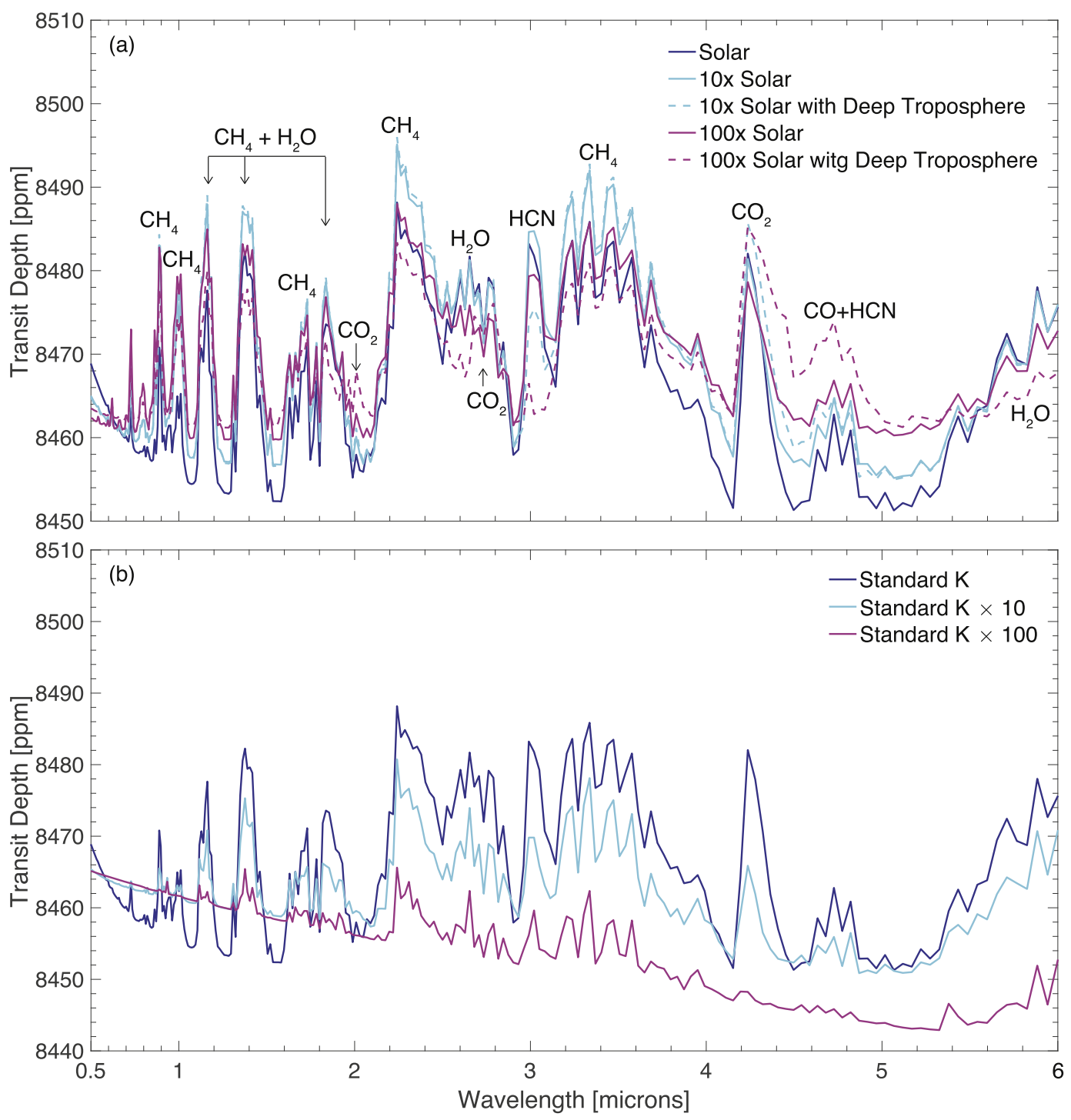

Figure 14. Modeled transmission spectra of the temperate gas giant $\mathrm{PH} 2 \mathrm{~b}$ for varied metallicities (a) and varied eddy diffusion coefficients at solar metallicity (b). The dashed lines show model spectra with a deep-tropospheric source of $\mathrm{CO}, \mathrm{CO}_{2}$, and $\mathrm{N}_{2}$ and sink of $\mathrm{NH}_{3}$. Several equilibrium gases $\left(\mathrm{CH}_{4}\right.$ and $\left.\mathrm{H}_{2} \mathrm{O}\right)$ and photochemical gases $\left(\mathrm{HCN}, \mathrm{CO}_{2}\right.$, and $\left.\mathrm{CO}\right)$ are detectable in the wavelength range $0.5-5.0 \mu \mathrm{m}$.

concept (Gaudi et al. 2020). While PH2 b and Kepler-167e themselves are not potential targets for these missions, their albedo spectra broadly resemble the targets in the temperate (PH2 b) and cold (Kepler-167 e) regimes.

The spectral features of $\mathrm{CH}_{4}$ and $\mathrm{H}_{2} \mathrm{O}$ can be seen in the reflected starlight of $\mathrm{PH} 2 \mathrm{~b}$. This ability to detect $\mathrm{H}_{2} \mathrm{O}$ in giant planets warmer than Jupiter is consistent with the finding of MacDonald et al. (2018). In addition to the absorption features of $\mathrm{CH}_{4}$ and $\mathrm{H}_{2} \mathrm{O}$, the albedo spectra of $\mathrm{PH} 2 \mathrm{~b}$ feature the absorption of the sulfur $\left(\mathrm{S}_{8}\right)$ haze layer at wavelengths shorter than $\sim 0.5 \mu \mathrm{m}$. This result is consistent with the findings of Gao et al. (2017). For a greater eddy diffusion coefficient, the sulfur haze layer is higher and the spectral features of $\mathrm{CH}_{4}$ and $\mathrm{H}_{2} \mathrm{O}$ become weaker. Interestingly, the absorption features of $\mathrm{H}_{2} \mathrm{O}$ are the most prominent in the solar abundance case, and they are somewhat swamped by the adjacent $\mathrm{CH}_{4}$ features at higher metallicities. This is because, as $\mathrm{H}_{2} \mathrm{O}$ condenses out, the abovecloud mixing ratio of $\mathrm{H}_{2} \mathrm{O}$ only slightly increases with the metallicity, while that of $\mathrm{CH}_{4}$ increases proportionally (Figure 7). Only the absorption of $\mathrm{CH}_{4}$ can be seen in the albedo spectra of Kepler-167e, as $\mathrm{H}_{2} \mathrm{O}$ is depleted by condensation. On both planets, the spectral features of $\mathrm{NH}_{3}$ are not seen due to its weak absorption (Irwin et al. 2018) and photochemical depletion to the cloud deck (Figures 7 and 8). The deep-tropospheric source and sink has minimal impact on the albedo spectra, unless in the $100 \times$ solar metallicity atmosphere on $\mathrm{PH} 2 \mathrm{~b}$ where a reduction of the $\mathrm{CH}_{4}$ features can be seen.

\section{Discussion}

The results and analyses presented in Section 3 indicate that the temperate and $\mathrm{H}_{2}$-rich exoplanets, particularly those orbiting M dwarf stars, provide an unprecedented opportunity to characterize the photochemical mechanisms in low-temperature atmospheres. So far, these planets include K2-18 b, TOI$1231 \mathrm{~b}$, and LHS- $1140 \mathrm{~b}$ if they have $\mathrm{H}_{2}$-dominated atmospheres. $\mathrm{H}_{2}$-dominated atmospheres that receive stellar irradiation equal to that of Earth are not found in the solar system, and we have shown here that this unique exoplanetary regime would result in mechanisms to form $\mathrm{HCN}$ as a uniformly 



Figure 15. Modeled transmission spectra of the cold gas giant Kepler-167 e for varied metallicities (a) and varied eddy diffusion coefficients at solar metallicity (b). The dashed lines show model spectra with a deep-tropospheric source of $\mathrm{CO}, \mathrm{CO}_{2}$, and $\mathrm{N}_{2}$ and sink of $\mathrm{NH}_{3}$. With the standard eddy diffusion coefficient, $\mathrm{CH}_{4}$ is the only detectable equilibrium gas and the photochemical gases $\mathrm{HCN}$ and $\mathrm{C}_{2} \mathrm{H}_{2}$ result in a small peak at $\sim 3 \mu \mathrm{m}$. The $100 \times$ solar metallicity atmosphere with a deeptropospheric source and sink can have detectable features of $\mathrm{CO}_{2}$ and $\mathrm{CO}$. Greater eddy diffusion coefficients can produce potentially detectable $\mathrm{NH}_{3}$.

abundant product from the photodissociation of $\mathrm{NH}_{3}$ in presence of $\mathrm{CH}_{4}$, as well as detectable levels of $\mathrm{CO}_{2}$ on planets around $\mathrm{G} / \mathrm{K}$ stars from the photodissociation of $\mathrm{CH}_{4}$ together with $\mathrm{H}_{2} \mathrm{O}$. The observations of temperate and $\mathrm{H}_{2}$-rich exoplanets thus promise to greatly expand the types of molecules detected in exoplanet atmospheres. Interestingly, $\mathrm{HCN}$ is one of the most important molecules for prebiotic chemistry (e.g., Patel et al. 2015), and the exoplanet observations may constrain the photochemical pathways for its formation in primordial planetary atmospheres.

For K2-18 b, our model predicts that the spectral features of $\mathrm{CH}_{4}$ can have a size of $\sim 80 \mathrm{ppm}$ in the transit depth, and those of $\mathrm{H}_{2} \mathrm{O}, \mathrm{NH}_{3}, \mathrm{HCN}$, and $\mathrm{CO}_{2}$ (from the deep troposphere) would have a size of $30 \sim 60 \mathrm{ppm}$. These quantities are substantially above the current estimate of the potential "noise floor" of the near-infrared instruments on JWST $(<\sim 10 \mathrm{ppm}$;
Schlawin et al. 2020, 2021), and are thus likely measurable. These spectral features may also be within the reach of ARIEL (Tinetti et al. 2018; Changeat et al. 2020).

An an example, we have used PandExo (Batalha et al. 2017) to estimate the overall photometric uncertainties achieved by observing the transits of $\mathrm{K} 2-18 \mathrm{~b}$ with the $\mathrm{G} 235 \mathrm{H}$ and $\mathrm{G} 395 \mathrm{H}$ gratings of the NIRSpec instrument on JWST. These two channels would cover the wavelength range $1.7-5.2 \mu \mathrm{m}$ and thus provide the sensitivity to the spectral features shown in Figure 13. We find that with two visits in $\mathrm{G} 235 \mathrm{H}$ and four visits in $\mathrm{G} 395 \mathrm{H}$, the overall photometric precision would be $\sim 20 \mathrm{ppm}$ per spectral element at the resolution of $R=100$ in both wavelength channels, and this precision should enable the detection of $\mathrm{CH}_{4}, \mathrm{H}_{2} \mathrm{O}, \mathrm{NH}_{3}$, the photochemical gas $\mathrm{HCN}$, and possibly $\mathrm{CO}_{2}$. If the spectral resolution is reduced to $R=50$, the number of visits could be halved, but this could cause 

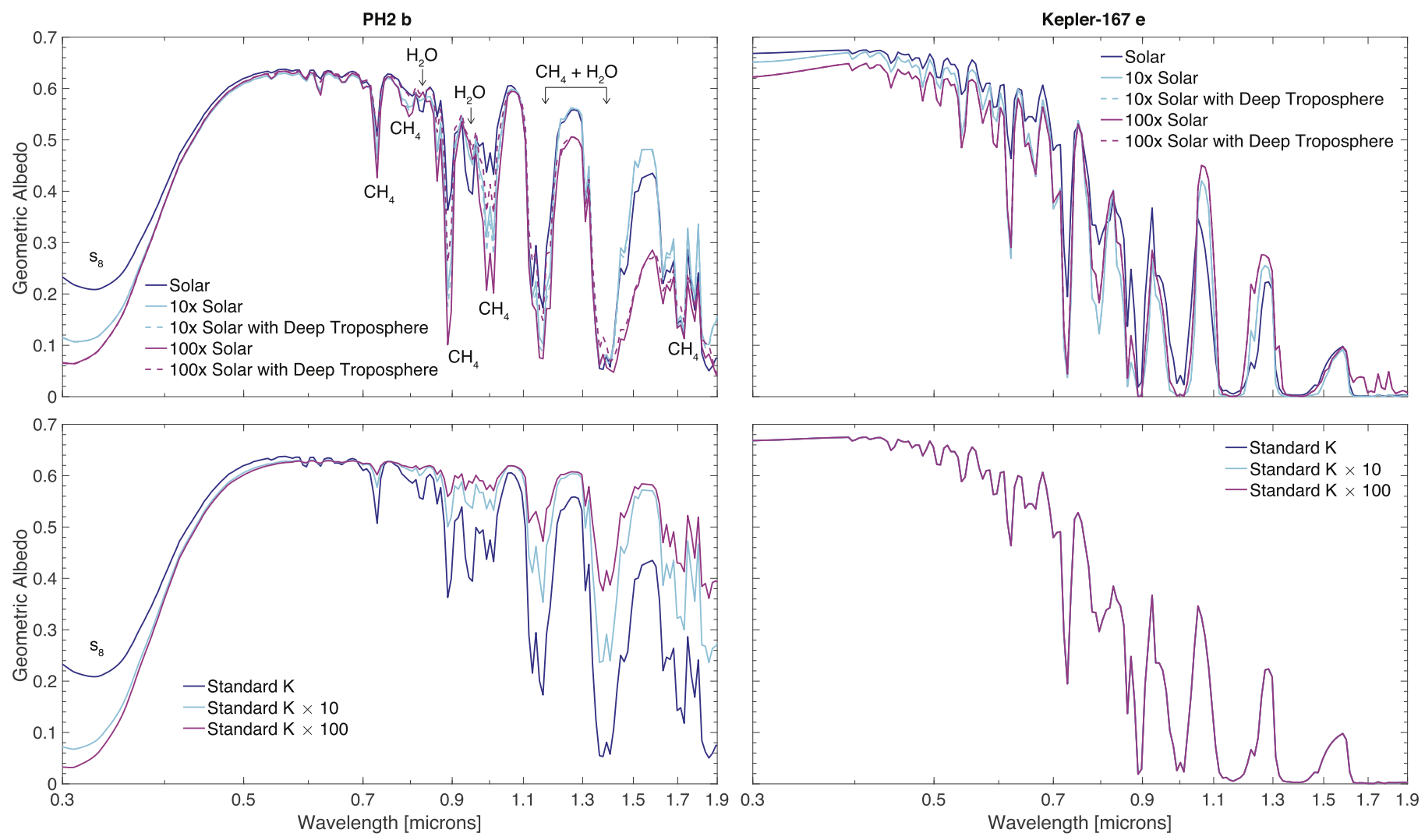

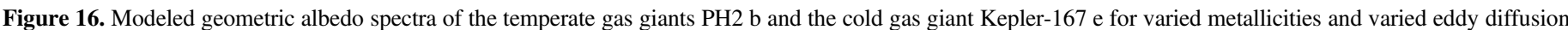

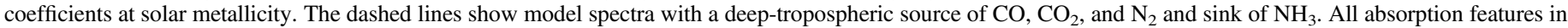

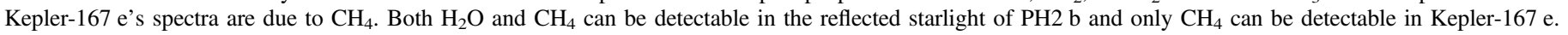

spectral ambiguity between $\mathrm{NH}_{3}$ and $\mathrm{HCN}$ because they both have absorption bands at $\sim 3.0 \mu \mathrm{m}$ (Figure 13). Spectral ambiguity in the transmission spectra with a resolution of $R \sim 50$ or less has been recently shown with HST at 1.1-1.7 $\mu \mathrm{m}$ (Mikal-Evans et al. 2020).

The size of the transmission spectral features expected for temperate and cold gas giants around $\mathrm{G} / \mathrm{K}$ stars, such as $\mathrm{PH} 2 \mathrm{~b}$ and Kepler-167 e, is small but probably not prohibitive. For example, our model predicts that the spectral features of $\mathrm{CH}_{4}$ can have a size of $\sim 50 \mathrm{ppm}$ in the transit depth, and those of $\mathrm{H}_{2} \mathrm{O}, \mathrm{CO}_{2}$, and $\mathrm{HCN}$ would have a size of $20 \sim 30 \mathrm{ppm}$. Several visits may need to be combined to achieve the photometric precision to detect these gases. Complementary to transmission spectroscopy, future direct-imaging missions can readily detect $\mathrm{CH}_{4}, \mathrm{H}_{2} \mathrm{O}$, and clouds (e.g., Damiano \& $\mathrm{Hu} 2020$ ), as well as the sulfur haze produced by atmospheric photochemistry.

While we focus on temperate and cold planets in this paper, the photochemical mechanisms and the predictions on the gas formation and spectral features should remain applicable to the planets that are only slightly warmer than $\mathrm{K} 2-18 \mathrm{~b}$ and $\mathrm{PH} 2 \mathrm{~b}$. This is because the results on these planets do not rely on the formation of water clouds. We suspect that the results should be applicable as long as the dominant $\mathrm{O}, \mathrm{C}, \mathrm{N}$, and $\mathrm{S}$ species in thermochemical equilibrium with $\mathrm{H}_{2}$ are $\mathrm{H}_{2} \mathrm{O}, \mathrm{CH}_{4}, \mathrm{NH}_{3}$, and $\mathrm{H}_{2} \mathrm{~S}$, and the assumptions on other atmospheric parameters (e.g., the eddy diffusion coefficient) remain broadly valid.

The eddy diffusion coefficient adopted in this work corresponds to that of Jupiter (Conrath \& Gierasch 1984) and features a minimum at the bottom of the stratosphere. This minimum value is also close to the eddy diffusion coefficient at the troposphere-stratosphere boundary of Earth's atmosphere (Massie \& Hunten 1981). However, the adopted eddy diffusion coefficient at the bottom of the stratosphere is smaller than the values used in past photochemical models of warmer exoplanets (e.g., GJ 1214b and GJ 436 b; Kempton et al. 2011; Moses et al. 2013; Hu \& Seager 2014) or the values derived from a 3D particulate tracer-transport model conditioned on hot Jupiters (Parmentier et al. 2013) by several orders of magnitude. We note that Earth, the cold giant planets in the solar system, and the modeled K2-18 b (Blain et al. 2021; Charnay et al. 2021) all have a temperature inversion and are thus true stratospheres, while atmosphere models of the warm exoplanets GJ 1214 b and GJ 436 b do not predict a temperature inversion (e.g., Kempton et al. 2011; Moses et al. 2013). The lower temperature and the temperature inversion may both contribute to the lower eddy diffusion coefficient on temperate and cold exoplanets. Predictive models of the eddy diffusion coefficient in exoplanets are being developed (e.g., Zhang \& Showman 2018a, 2018b) and can be tested by future observations as shown in Figures 13-15.

We have also shown in Section 3 that the deep-tropospheric source of $\mathrm{CO}, \mathrm{CO}_{2}$, and $\mathrm{N}_{2}$ and sink of $\mathrm{NH}_{3}$ can substantially change the composition of the observable part of the atmosphere-and the transmission spectrum-if the atmosphere has $100 \times$ solar metallicity. The main change is the reduction of $\mathrm{NH}_{3}$ and $\mathrm{HCN}$ and the enhancement of $\mathrm{CO}$ and $\mathrm{CO}_{2}$ in the spectrum. As such, detecting and measuring the abundance of these gases in the temperate $\mathrm{H}_{2}$-dominated atmosphere may provide constraints on the temperature and the 
strength of vertical mixing in the deep troposphere (e.g., Fortney et al. 2020). One should note that modification of the deep-tropospheric abundance of gases by photochemical processes will be important in this endeavor: $\mathrm{NH}_{3}$ is expected to be depleted anyway and $\mathrm{CO}_{2}$ should overtake $\mathrm{CO}$ as the main carbon molecule in the middle atmosphere of temperate and $\mathrm{H}_{2}$-rich exoplanets of $\mathrm{G} / \mathrm{K}$ stars.

A recently published study of atmospheric photochemistry in the atmosphere of K2-18 b (Yu et al. 2021) came to our notice during the peer-review phase of this work. The "no-surface" case in Yu et al. (2021) has a comparable physical picture as the $100 \times$ solar metallicity case with the deep-tropospheric source and sink presented in Figure 6. A common feature is that such an atmosphere would be rich in $\mathrm{CO}$ and $\mathrm{CO}_{2}$, and the difference in the profiles of $\mathrm{HCN}$ and other photochemical gases between the models may be due to the assumed profile of eddy diffusivity.

Lastly, we emphasize that several effects of potential importance have not been studied in this work. A more accurate pressure-temperature profile from 1D or 3D models may improve the prediction on the extent of water vapor depletion by condensation. A temperature inversion would result in higher temperatures in the upper stratosphere than what has been adopted here, and this may have an impact on the efficacy and relative importance of chemical pathways. A more accurate pressure-temperature profile and vertical mixing modeling for the deep troposphere may improve the prediction and perhaps remove the need for the endmember scenarios as presented. On planets that are expected to be tidally locked, the transmission spectra are controlled by the chemical abundance at the limb (e.g., Steinrueck et al. 2019; Drummond et al. 2020), and thus the horizontal transport of long-lived photochemical gases such as $\mathrm{HCN}$ and $\mathrm{CO}_{2}$ may be important. Finally, we have not included hydrocarbon haze in this study, though it can form with both $\mathrm{C}_{2} \mathrm{H}_{2}$ and $\mathrm{HCN}$ in the atmosphere (Kawashima et al. 2019). We hope that the present work will help motivate future studies to address these potential effects.

\section{Conclusion}

We have studied the photochemical mechanisms in temperate/cold and $\mathrm{H}_{2}$-rich exoplanets. For the $\mathrm{H}_{2}$-rich planets (giants and mini-Neptunes) that receive stellar irradiance of approximately Earth's, we find that the main photochemical gases are $\mathrm{HCN}$ and $\mathrm{N}_{2}$. The synthesis of $\mathrm{HCN}$ requires the photodissociation of $\mathrm{NH}_{3}$ in the presence of $\mathrm{CH}_{4}$ at a temperature $>\sim 200 \mathrm{~K} . \mathrm{NH}_{3}$ is dissociated near the water cloud deck and thus has a minimal mixing ratio in the middle atmosphere $\left(10-10^{3} \mathrm{~Pa}\right)$ if the planet orbits a $\mathrm{G} / \mathrm{K}$ star, but $\mathrm{NH}_{3}$ can remain intact in the middle atmosphere if the planet orbits an $\mathrm{M}$ star. Additional photochemical gases include $\mathrm{CO}$, $\mathrm{CO}_{2}, \mathrm{C}_{2} \mathrm{H}_{6}$, and $\mathrm{C}_{2} \mathrm{H}_{2}$. $\mathrm{CO}$ and $\mathrm{CO}_{2}$ are the main photochemical gas of carbon because of the photodissociation of $\mathrm{H}_{2} \mathrm{O}$ together with $\mathrm{CH}_{4}$. The photodissociation of $\mathrm{H}_{2} \mathrm{O}$ also strongly limits the abundance of photochemical hydrocarbons in the atmosphere. For the planets that receive stellar irradiance of approximately $0.1 \times$ Earth's, the formation of $\mathrm{HCN}$ is limited by the low temperature, $\mathrm{CO}_{2}$ or $\mathrm{CO}$ is not produced due to the nearly complete removal of $\mathrm{H}_{2} \mathrm{O}$ by condensation, and the main photochemical gases are $\mathrm{C}_{2} \mathrm{H}_{6}$ and $\mathrm{C}_{2} \mathrm{H}_{2}$.

The photochemical models of the temperate sub-Neptune $\mathrm{K} 2-18 \mathrm{~b}$ assuming $1-100 \times$ solar abundances result in transmission spectra that fit the current measurements from $\mathrm{K} 2$,
HST, and Spitzer. Both $\mathrm{CH}_{4}$ and $\mathrm{H}_{2} \mathrm{O}$ contribute to the spectral modulation seen by HST. Transmission spectroscopy with JWST and ARIEL will likely provide the sensitivity to detect the equilibrium gases $\mathrm{CH}_{4}, \mathrm{H}_{2} \mathrm{O}$, and $\mathrm{NH}_{3}$, the photochemical gas $\mathrm{HCN}$, and in some cases $\mathrm{CO}_{2} \cdot \mathrm{C}_{2} \mathrm{H}_{6}$ is unlikely to be detectable due to its low mixing ratio and spectral feature overwhelmed by $\mathrm{CH}_{4}$. Transmission spectroscopy of the temperate giant planets around $\mathrm{G} / \mathrm{K}$ stars will likely provide the sensitivity to detect $\mathrm{CH}_{4}, \mathrm{H}_{2} \mathrm{O}$, and the photochemical gases $\mathrm{HCN}$ and $\mathrm{CO}_{2}$, complementing future spectroscopy in the reflected light by direct imaging. If the eddy diffusion coefficient is greater than that in Jupiter by two orders of magnitude, the sulfur haze layer would subdue the transmission spectral features-but this situation is unlikely for $\mathrm{K} 2-18 \mathrm{~b}$ because of the detected spectral modulation. These results are also applicable to similarly irradiated $\mathrm{H}_{2}$-rich exoplanets, including TOI-1231 b and LHS-1140 b if they have $\mathrm{H}_{2}$-dominated atmospheres.

The results here indicate that the temperate/cold and $\mathrm{H}_{2}$-rich exoplanets, which often represent a temperature and atmospheric composition regime that is not found in the solar system, likely have rich chemistry above clouds that leads to a potpourri of photochemical gases, some of which will build up to the abundance detectable by transmission spectroscopy soon. The detection of atmospheric photochemical products in $\mathrm{K} 2$ $18 \mathrm{~b}$ and other temperate exoplanets would expand the types of molecules detected in exoplanet atmospheres and greatly advance our understanding of the photochemical processes at works in low-temperature exoplanets.

We thank Sara Seager and the anonymous referee for helpful comments that improved the paper, Yuk Yung and Danica Adams for providing information on the Caltech/JPL KINETICS code for comparison, and Mario Damiano for advice on the PandExo simulations. This work was supported in part by the NASA Exoplanets Research Program grant \#80NM0018F0612. This research was carried out at the Jet Propulsion Laboratory, California Institute of Technology, under a contract with the National Aeronautics and Space Administration.

\section{ORCID iDs}

Renyu Hu (i) https://orcid.org/0000-0003-2215-8485

\section{References}

Agúndez, M., Venot, O., Selsis, F., \& Iro, N. 2014, ApJ, 781, 68

Airapetian, V., Glocer, A., Gronoff, G., Hebrard, E., \& Danchi, W. 2016, NatGe, 9, 452

Atreya, S., \& Romani, P. 1985, Recent Advances in Planetary Meteorology (Cambridge: Cambridge Univ. Press), 17

Atreya, S. K., Donahue, T. M., \& Kuhn, W. R. 1977, Icar, 31, 348

Atreya, S. K., Wong, M. H., Owen, T. C., et al. 1999, P\&SS, 47, 1243

Barclay, T., Pepper, J., \& Quintana, E. V. 2018, ApJS, 239, 2

Batalha, N. E., Mandell, A., Pontoppidan, K., et al. 2017, PASP, 129, 064501 Baulch, D., Cobos, C., Cox, R., et al. 1992, JPCRD, 21, 411

Beichman, C., Benneke, B., Knutson, H., et al. 2014, PASP, 126, 1134 Benneke, B., Wong, I., Piaulet, C., et al. 2019, ApJL, 887, L14

Berger, T. A., Huber, D., Gaidos, E., \& van Saders, J. L. 2018, ApJ, 866, 99 Blain, D., Charnay, B., \& Bézard, B. 2021, A\&A, 646, A15

Blumenthal, S. D., Mandell, A. M., Hébrard, E., et al. 2018, ApJ, 853, 138 Burrows, A., Hubbard, W. B., Lunine, J., \& Liebert, J. 2001, RvMP, 73, 719 Burrows, A., \& Sharp, C. 1999, ApJ, 512, 843

Burt, J. A., Dragomir, D., Mollière, P., et al. 2021, AJ, 162, 87

Changeat, Q., Edwards, B., Al-Refaie, A. F., et al. 2020, arXiv:2003.01486

Charnay, B., Blain, D., Bézard, B., et al. 2021, A\&A, 646, A171 
Cloutier, R., Astudillo-Defru, N., Doyon, R., et al. 2019, A\&A, 621, A49

Conrath, B. J., \& Gierasch, P. J. 1984, Icar, 57, 184

Damiano, M., \& Hu, R. 2020, AJ, 159, 175

Davis, G., Naylor, D., Griffin, M. J., Clark, T., \& Holland, W. S. 1997, Icar, 130, 387

De Pater, I., Romani, P. N., \& Atreya, S. K. 1989, Icar, 82, 288

De Wit, J., Wakeford, H. R., Lewis, N. K., et al. 2018, NatAs, 2, 214

Dobrijevic, M., Loison, J., Hue, V., Cavalié, T., \& Hickson, K. 2020, Icar, 335, 113375

dos Santos, L. A., Ehrenreich, D., Bourrier, V., et al. 2020, A\&A, 634, L4

Drummond, B., Hébrard, E., Mayne, N. J., et al. 2020, A\&A, 636, A68

Fegley, B., Jr., \& Lodders, K. 1996, ApJL, 472, L37

Fortney, J. J., Mordasini, C., Nettelmann, N., et al. 2013, ApJ, 775, 80

Fortney, J. J., Visscher, C., Marley, M. S., et al. 2020, AJ, 160, 288

France, K., Loyd, R. P., Youngblood, A., et al. 2016, ApJ, 820, 89

Gao, P., Marley, M. S., Zahnle, K., Robinson, T. D., \& Lewis, N. K. 2017, AJ, 153,139

Gaudi, B. S., Seager, S., Mennesson, B., et al. 2020, arXiv:2001.06683

Gierasch, P., \& Conrath, B. 1985, Recent Advances in Planetary Meteorology (Cambridge: Cambridge Univ. Press), 121

Gladstone, G. R., Allen, M., \& Yung, Y. 1996, Icar, 119, 1

Heng, K., \& Tsai, S.-M. 2016, ApJ, 829, 104

Hobbs, R., Shorttle, O., Madhusudhan, N., \& Rimmer, P. 2019, MNRAS, 487, 2242

Hu, R. 2019, ApJ, 887, 166

Hu, R., \& Seager, S. 2014, ApJ, 784, 63

Hu, R., Seager, S., \& Bains, W. 2012, ApJ, 761, 166

Hu, R., Seager, S., \& Bains, W. 2013, ApJ, 769, 6

Irwin, P. G., Bowles, N., Braude, A. S., Garland, R., \& Calcutt, S. 2018, Icar, 302,426

Kasdin, N. J., Bailey, V., Mennesson, B., et al. 2020, Proc. SPIE, 11443, $114431 \mathrm{U}$

Kawashima, Y., Hu, R., \& Ikoma, M. 2019, ApJL, 876, L5

Kawashima, Y., \& Ikoma, M. 2018, ApJ, 853, 7

Kaye, J. A., \& Strobel, D. F. 1983a, Icar, 55, 399

Kaye, J. A., \& Strobel, D. F. 1983b, Icar, 54, 417

Kempton, E. M.-R., Zahnle, K., \& Fortney, J. J. 2011, ApJ, 745, 3

Kipping, D. M., Torres, G., Henze, C., et al. 2016, ApJ, 820, 112

Krasnopolsky, V. A. 2009, Icar, 201, 226

Krasnopolsky, V. A. 2014, Icar, 236, 83

Läuter, A., Lee, K., Jung, K., et al. 2002, CPL, 358, 314

Lavvas, P., Coustenis, A., \& Vardavas, I. 2008, P\&SS, 56, 67

Lavvas, P., Koskinen, T., Steinrueck, M. E., Muñoz, A. G., \& Showman, A. P. 2019, ApJ, 878, 118

Lewis, J. S. 1969, Icar, 10, 365

Lindzen, R. S. 1981, JGRC, 86, 9707

Line, M. R., Vasisht, G., Chen, P., Angerhausen, D., \& Yung, Y. L. 2011, ApJ, 738, 32

MacDonald, R. J., Marley, M. S., Fortney, J. J., \& Lewis, N. K. 2018, ApJ, 858, 69

Madhusudhan, N., Nixon, M. C., Welbanks, L., Piette, A. A., \& Booth, R. A. 2020, ApJL, 891, L7

Martonchik, J. V., Orton, G. S., \& Appleby, J. F. 1984, ApOpt, 23, 541

Massie, S., \& Hunten, D. 1981, JGRC, 86, 9859
Mikal-Evans, T., Crossfield, I. J., Benneke, B., et al. 2020, AJ, 161, 18

Molaverdikhani, K., Henning, T., \& Mollière, P. 2019, ApJ, 883, 194

Mollière, P., van Boekel, R., Dullemond, C., Henning, T., \& Mordasini, C. 2015, ApJ, 813, 47

Morley, C. V., Marley, M. S., Fortney, J. J., et al. 2014, ApJ, 787, 78

Morrissey, P. F., Feldman, P. D., McGrath, M. A., Wolven, B. C., \& Moos, H. W. 1995, ApJL, 454, L65

Moses, J., Fouchet, T., Bézard, B., et al. 2005, JGRE, 110, E08001

Moses, J. I., Line, M. R., Visscher, C., et al. 2013, ApJ, 777, 34

Moses, J. I., Madhusudhan, N., Visscher, C., \& Freedman, R. S. 2013, ApJ, 763,25

Moses, J. I., Marley, M. S., Zahnle, K., et al. 2016, ApJ, 829, 66

Moses, J. I., Visscher, C., Fortney, J. J., et al. 2011, ApJ, 737, 15

Moses, J. I., Visscher, C., Keane, T. C., \& Sperier, A. 2010, FaDi, 147, 103

Palmer, K. F., \& Williams, D. 1974, JOSA, 64, 1107

Parmentier, V., Showman, A. P., \& Lian, Y. 2013, A\&A, 558, A91

Patel, B. H., Percivalle, C., Ritson, D. J., Duffy, C. D., \& Sutherland, J. D 2015, NatCh, 7, 301

Perry, R., \& Green, D. 2007, Perry's Chemical Engineers' Handbook (8th ed; New York: McGraw-Hill)

Piette, A. A., \& Madhusudhan, N. 2020, ApJ, 904, 154

Ranjan, S., Schwieterman, E. W., Harman, C., et al. 2020, ApJ, 896, 148

Rimmer, P. B., \& Rugheimer, S. 2019, Icar, 329, 124

Romani, P. N., De Pater, I., \& Atreya, S. K. 1989, GeoRL, 16, 933

Schlawin, E., Leisenring, J., McElwain, M. W., et al. 2021, AJ, 161, 115

Schlawin, E., Leisenring, J., Misselt, K., et al. 2020, AJ, 160, 231

Seager, S., Kasdin, N. J., Booth, J., et al. 2019, BAAS, 51, 106

Seiff, A., Kirk, D. B., Knight, T. C., et al. 1998, JGRE, 103, 22857

Simon-Miller, A. A., Conrath, B. J., Gierasch, P. J., et al. 2006, Icar, 180, 98

Steinrueck, M. E., Parmentier, V., Showman, A. P., Lothringer, J. D., \& Lupu, R. E. 2019, ApJ, 880, 14

Strobel, D. F. 1973, JAtS, 30, 1205

Thorngren, D. P., Fortney, J. J., Murray-Clay, R. A., \& Lopez, E. D. 2016, ApJ, 831, 64

Tinetti, G., Drossart, P., Eccleston, P., et al. 2018, ExA, 46, 135

Tsai, S.-M., Kitzmann, D., Lyons, J. R., et al. 2018, ApJ, 862, 31

Tsiaras, A., Waldmann, I. P., Tinetti, G., Tennyson, J., \& Yurchenko, S. N. 2019, NatAs, 3, 1086

Venot, O., Hébrard, E., Agúndez, M., et al. 2012, A\&A, 546, A43

Visscher, C., \& Moses, J. I. 2011, ApJ, 738, 72

Visscher, C., Moses, J. I., \& Saslow, S. A. 2010, Icar, 209, 602

Vuitton, V., Yelle, R., Klippenstein, S., Hörst, S., \& Lavvas, P. 2019, Icar, 324,120

Waite, J., Cravens, T., Kozyra, J., et al. 1983, JGRA, 88, 6143

Wang, J., Fischer, D. A., Barclay, T., et al. 2013, ApJ, 776, 10

Woitke, P., Herbort, O., Helling, C., et al. 2021, A\&A, 646, A43

Yelle, R. V., Griffith, C. A., \& Young, L. A. 2001, Icar, 152, 331

Yu, X., Moses, J. I., Fortney, J. J., \& Zhang, X. 2021, ApJ, 914, 38

Yung, Y. L., Allen, M., \& Pinto, J. P. 1984, ApJS, 55, 465

Zahnle, K., Marley, M. S., Morley, C. V., \& Moses, J. I. 2016, ApJ, 824, 137

Zahnle, K. J., \& Marley, M. S. 2014, ApJ, 797, 41

Zhang, X., \& Showman, A. P. 2018a, ApJ, 866, 1

Zhang, X., \& Showman, A. P. 2018b, ApJ, 866, 2

Zhang, Z., Zhou, Y., Rackham, B. V., \& Apai, D. 2018, AJ, 156, 178 